\title{
Associação entre o peso ao nascer, o estado nutricional e o crescimento transversal do maxilar: implicações para a saúde materna e infantil
}

\section{Laura Jackeline García Rincón}

\author{
Dissertação apresentada ao \\ Programa de Pós-Graduação em \\ Saúde Pública da Faculdade de \\ Saúde Pública da Universidade de \\ São Paulo para obtenção do título de \\ Mestre em Ciências \\ Área de concentração: Saúde Pública \\ Orientador: Prof. Dr. Paulo Frazão
}

\section{Versão corrigida \\ São Paulo \\ 2017}


Autorizo a reprodução e divulgação total ou parcial deste trabalho, por qualquer meio convencional ou eletrônico, para fins de estudo e pesquisa, desde que citada a fonte.

\section{Catalogação da Publicação}

Biblioteca/CIR: Centro de Informação e Referência em Saúde Pública Faculdade de Saúde Pública da

Universidade de São Paulo

Dados fornecidos pelo(a) autor(a)

Rincon, Laura

- Associação entre o peso ao nascer, o estado nutricional e o crescimento transversal do maxilar: implicações para a saúde materna e infantil / Laura Rincon; orientador Paulo Frazão. -- São Paulo, 2017. $74 \mathrm{p}$.

Dissertação (Mestrado) -- Faculdade de Saúde Pública da Universidade de São Paulo, 2017.

1. Crescimento transversal do maxilar. 2. Peso ao nascer. 3. Alimentação artificial. 4. Escore Z do IMC para a idade. 5. Vigilância sanitária. I. Frazão, Paulo, orient. II. Título. 


\begin{abstract}
Ao meu pai,
por todo seu apoio sempre porque sem ele este mestrado não teria sido possível

À minha mãe, por seu amor incondicional e compreensão infinita

À minha irmã, que me acompanhou neste processo.
\end{abstract}

Minha querida família, motivo de orgulho e admiração. 


\section{AGRADECIMENTOS}

Agradeço aos meus pais, Carlos García e Constanza Rincón, que me apoiaram sempre em todas minhas escolhas. É por eles que eu sou a pessoa que sou hoje. Nunca poderei agradecer o suficiente a eles por todo o esforço que sempre fizeram por minha irmã e por mim. Por não colocar limites aos meus sonhos e me encorajar a procurar alcançar objetivos cada vez maiores.

A minha irmã Diana, quero agradecer que sempre esteve comigo aqui no Brasil. Pela sua ajuda e conselhos, sua paciência e compreensão em momentos difíceis longe da família e do país.

A meu orientador, o Prof. Paulo Frazão, por ter aceitado me orientar, acreditar em mim e contribuir na minha formação como sanitarista. São muitas as coisas que eu aprendi com ele e pelas quais me sinto muito grata. Ter a oportunidade de trabalhar com uma pessoa como ele foi um privilégio e um grande orgulho para mim. Obrigada por ter aberto as portas do Brasil para mim.

Ao Prof. Gizelton Pereira Alencar que contribuiu de maneira muito importante a este trabalho com seus conhecimentos e auxilio na análise dos dados. Obrigada pela sua boa disposição para ajudar no desenvolvimento do projeto.

À Profa. Jenny Abanto por suas importantes recomendações durante o exame de qualificação que ajudaram no progresso do trabalho.

À Profa. Marly Cardoso e o Prof. Paulo Capel Narvai que possibilitaram a execução do estudo longitudinal em Acrelândia.

Aos amigos e companheiros que conheci aqui no Brasil e àquelas valiosas pessoas que deixei na Colômbia e me acompanharam a distância sempre no processo do meu mestrado. A Checho pela companhia nesta etapa da minha vida. 
Agradeço às famílias de Acrelândia que participaram neste trabalho, esperando que cada estudo realizado lá ajude no progresso da região e da qualidade de vida dos seus habitantes.

Muito obrigada, Laura Jackeline García Rincón 
RINCON, L.J.G. Associação entre o peso ao nascer, o estado nutricional e o crescimento transversal do maxilar: implicações para a saúde materna e infantil. 2017. Dissertação - Faculdade de Saúde Pública da USP, São Paulo, 2017.

\section{RESUMO}

O crescimento é um processo dinâmico que muda ao longo da vida. $O$ crescimento ósseo é um evento multicausal no qual, além dos fatores biológicos, intervêm outras características como as relacionadas ao nível socioeconômico, à raça, ao período perinatal, aos hábitos, entre outros. Este estudo objetivou identificar fatores associados ao crescimento transversal do osso maxilar representado pela medida da distância intermolar superior. Foi realizado um estudo seccional aninhado numa coorte, com uma amostra de 158 crianças entre 7 e 9 anos de idade das escolas urbanas de Acrelândia, município da Amazônia Ocidental Brasileira. A variável dependente foi a distância intermolar superior, medida entre as fossas centrais dos primeiros molares superiores permanentes. A partir da idade da introdução da mamadeira foi desenvolvida uma escala assumindo valores de 1 a 10 . O sexo, o peso ao nascer, o padrão de uso da mamadeira e o escore $Z$ do índice de massa corporal (IMC) para a idade foram consideradas como variáveis independentes, sendo analisadas por meio de modelo de equações estruturais (MEE). Foram estimados os coeficientes padronizados (CP) para os efeitos diretos positivos significativos do sexo $(C P=0,203 ; p=0,007)$, peso ao nascer $(C P=0,155 ; p=0,046)$ e escore $Z$ do IMC para a idade $(C P=0,165 ; p=0,030)$ sobre o crescimento transversal do maxilar. Os efeitos indiretos $(C P=0,058 ; p=0,029)$ e o efeito total $(C P=0,262 ; p=0,000)$ do sexo sobre o desfecho mostraram significância estatística. Os efeitos indiretos do peso ao nascer sobre o desfecho não foram significativos ( $\mathrm{CP}=0,018 ; \mathrm{p}=0,508)$, porém, $o$ efeito total foi significativo ( $C P=0,174 ; p=0,023)$. Em conclusão, o sexo, o peso ao nascer, a idade de introdução da mamadeira e o escore $Z$ do IMC para a idade 
associam-se ao crescimento transversal do osso maxilar. Além de contribuir para um adequado peso ao nascer da criança, políticas e programas que favoreçam o cuidado pré natal e condições para garantir um parto a termo podem repercutir positivamente no crescimento transversal do maxilar. Do ponto de vista da Vigilância em Saúde, crianças com peso ao nascer diminuído, padrão inadequado de aleitamento materno e déficit nutricional para a idade podem apresentar maior probabilidade de desenvolver atrofia dos maxilares podendo, conforme a gravidade, redundar numa oclusopatia com importante impacto na qualidade de vida.

Palavras chave: Crescimento transversal do maxilar, sexo, peso ao nascer, alimentação artificial, escore $Z$ do IMC para a idade, vigilância sanitária. 
RINCON, L.J.G. Association between birthweight, nutritional status and transverse growth of the maxillary bone: implications for the maternal and child health. 2017. Dissertação - Faculdade de Saúde Pública da USP, São Paulo, 2017.

\begin{abstract}
Growth is a dynamic process that changes throughout life. Bone growth is a multicausal event in which other characteristics such as socioeconomic level, race, perinatal period, habits, and others are involved in addition to biological factors. This study aimed to identify with the associated factors transverse growth of the maxillary bone represented by the superior intermolar distance. A cross-sectional survey nested in a population-based cohort study was conducted with a sample of 158 children aged 7 to 9 years old from the urban schools of Acrelandia, a small town in the Brazilian Western Amazon. The dependent variable was the upper intermolar distance measured between the central fossae of the first permanent maxillary molars. From the age of bottle introduction, a scale was developed assuming values from 1 to 10 . Sex, birth weight, bottle introduction scale and $Z$ score of body mass index (BMI) for age (BAZ) were considered as independent variables, being analyzed with structural equations model (SEM). The standardized coefficients were estimated for the significant direct positive effects of sex $(S C=0.203 ; p=0.007)$, birth weight $(S C=0.155 ; p=0.046)$ and $B A Z(S C=0.165$; $p=0.030$ ) on transverse maxillary growth were found. The indirect effects $(\mathrm{SC}=0.058 ; \mathrm{p}=0.029)$ and the total effect $(\mathrm{SC}=0.262 ; \mathrm{p}=0.000)$ of sex on the outcome were statistically significant. The indirect effects of birth weight on outcome were not significant $(\mathrm{SC}=0.018 ; \mathrm{p}=0.508)$, however, the total effect was significant ( $\mathrm{SC}=0.174 ; \mathrm{p}=0.023$ ). In conclusion, sex, birth weight, bottle beginning age and BMI $Z$ score for age showed association with the transverse growth of the maxillary bone. In addition to contributing to an adequate birth weight of the child, policies and programs that favor prenatal care and conditions to guarantee a fullterm birth can positively affect transversal growth of the maxilla. From a Health
\end{abstract}


Surveillance point of view, children with reduced birth weight, inadequate breastfeeding pattern and nutritional deficit for age may be more likely to develop atrophy of the jaws which, depending on the severity, may result in malocclusion with an important impact on quality of life.

Keywords: Transverse growth of the maxilla, sex, birth weight, bottle feeding, BMIfor-age $z$-score, health surveillance. 


\section{LISTA DE ABREVIATURAS E SIGLAS}

ANOVA - Análise de variância

CFI - Índice de ajuste comparativo

CP - Coeficiente padronizado

IBGE - Instituto Brasileiro de Geografia e Estatística

IDH - Índice de Desenvolvimento Humano

IMC - Índice de massa corporal

OMS - Organização Mundial da Saúde

OPS - Organização Pan-americana da Saúde

MEE - Modelo de equações estruturais

MLR - Máxima Verossimilhança Robusta

PNUD - Programa das Nações Unidas para o Desenvolvimento no Brasil

RMSEA - Raiz da média dos quadrados dos erros de aproximação

TLI - Índice de Tucker Lewis

UFAC - Universidade Federal do Acre

UNICEF - Fundo das Nações Unidas para a Infância 


\section{SUMÁRIO}

Página

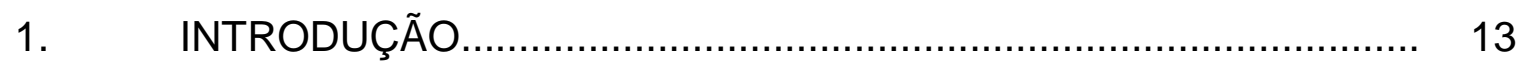

2. REVISÃO DA LITERATURA..................................................... 16

2.1. OSSO MAXILAR .................................................................. 16

2.1.1. Crescimento do maxilar............................................................ 17

2.1.2. Crescimento diminuído do maxilar.............................................. 19

2.1.3. Técnicas de mensuração transversal do maxilar.............................. 21

2.2. PESO AO NASCER ........................................................... 26

2.2.1. Aspectos do peso ao nascer..................................................... 26

2.2.2. Peso ao nascer e a cavidade bucal............................................... 27

2.3. ALEITAMENTO DA CRIANÇA .................................................. 29

2.3.1. Tipos de aleitamento............................................................. 29

2.3.2. O tipo de aleitamento e a cavidade bucal....................................... 31

2.4. ESTADO NUTRICIONAL............................................................ 34

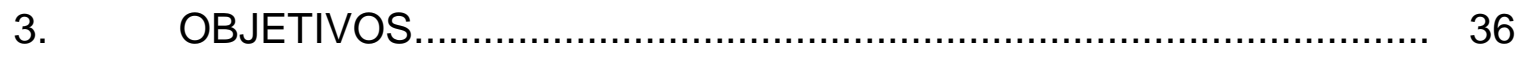

3.1. Objetivo geral.................................................................. 36

3.2. Objetivos específicos............................................................. 36

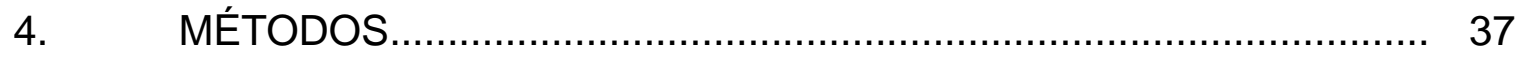

4.1. Desenho do estudo............................................................... 37

4.2. População do estudo............................................................... 38

4.3. Variáveis do estudo................................................................. 40

4.4. Coleta dos dados................................................................. 43

4.5. Controle das observações........................................................... 43

4.6. Análise dos dados................................................................ 44

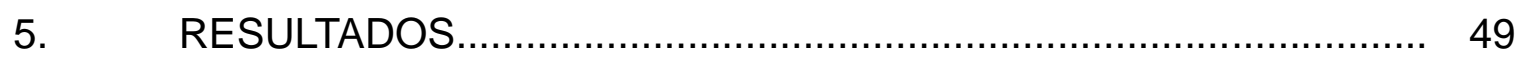

5.1. Caracterização da amostra...................................................... 49

5.2. Modelo estrutural............................................................... 50

5.3. Efeitos diretos das variáveis independentes sobre o desfecho......... 51

5.4. Efeitos indiretos das variáveis independentes sobre o desfecho....... 53

5.5 Associações entre variáveis independentes.................................. 54 


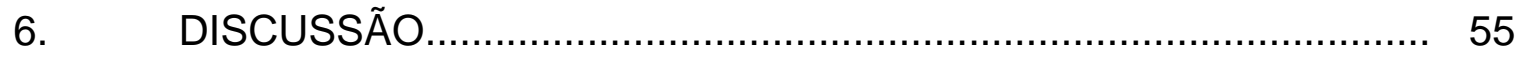

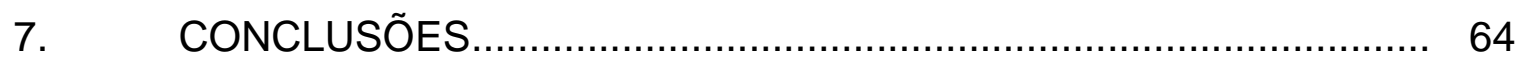

8. REFERÊNCIAS.................................................................. 65

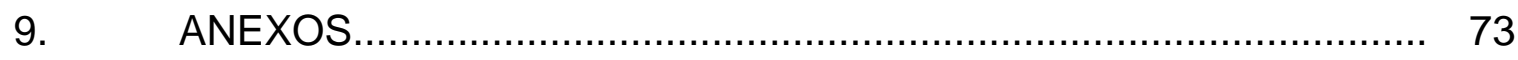

9.1 Anexo 1. Termo de Consentimento Livre e Esclarecido - TCLE........ 73

9.2 Anexo 2. Aprovação do comitê de ética em pesquisa - COEP/FSP.. 74 


\section{INTRODUÇÃO}

Nesta dissertação, estuda-se o crescimento ósseo como evento dinâmico e multicausal que muda ao longo da vida; e no qual, além dos fatores biológicos, intervêm outras características como as relacionadas ao nível socioeconômico, à raça, ao período perinatal, aos hábitos e outros comportamentos que muitas vezes estão além da própria pessoa e dependem de um terceiro, como por exemplo, a alimentação da criança nos primeiros anos de vida (Frazão e Narvai, 2013).

No caso deste trabalho, analisou-se a distância intermolar como característica representativa do crescimento transversal do osso maxilar, identificando fatores possivelmente associados a ele.

As alterações transversais dos maxilares podem derivar em oclusopatias como mordida cruzada posterior, apinhamento dentário e assimetrias. Além disso, os planos vertical e anteroposterior poderiam sofrer variações (Araujo \& Buschang, 2004).

Estudos sugerem a relação que o aleitamento materno pode ter com o processo de crescimento do maxilar, além dos efeitos que sua ausência ou sua curta duração podem ocasionar; tais como má oclusão e hábitos de sucção não nutritiva (Maia-Nader et al., 2014; Peres et al., 2015). O uso de mamadeiras tem sido relacionado à aparição de cáries em decorrência da adição de açúcar ao leite bovino; o que não acontece com o leite materno (Avila et al., 2015). Dada a importância do aleitamento materno sobre as funções de respiração, sucção e deglutição nos primeiros seis meses de vida, que preparam a criança para os movimentos de mastigação e fonação que irá desenvolver com o tempo, torna-se fundamental o estudo do aleitamento materno no contexto do desenvolvimento das estruturas craniofaciais.

Os hábitos de sucção não nutritiva, tais como o uso de bicos, alteram a tonicidade muscular e o correto desempenho de funções orofaciais adequadas como a deglutição e a fonação; contribuindo para a aparição de deglutição atípica, má oclusão, entre outros (Abanto et al., 2014). 
Outro aspecto a ser considerado foi o peso ao nascer. O baixo peso ao nascer pode produzir consequências desfavoráveis para 0 desenvolvimento e 0 crescimento geral da criança, além de outras condições como suscetibilidade a algumas doenças respiratórias e digestivas, entre outras. As crianças com baixo peso ao nascer são consideradas como um grupo que estará em situação de risco de doença durante a infância e a vida adulta, sendo condicionado pela nutrição que receba. Crianças com peso insuficiente ao nascer (entre $2.500 \mathrm{~g}$ e $2.999 \mathrm{~g}$ ) têm maior taxa de mortalidade infantil, doenças infecciosas ou respiratórias e de ocorrência de doenças crônicas. O peso insuficiente ao nascer ocorre com maior frequência que o baixo peso ao nascer e também representa uma maior chance de atraso no crescimento e desenvolvimento geral da criança (Azenha et al., 2008; Antonio et al., 2009; Barbas et al., 2009). No entanto, esse ramo da medicina, ainda não foi muito estudado pelo campo da odontologia e é pertinente propor pesquisas que integrem essas áreas e façam com que o diagnóstico e 0 tratamento sejam multidisciplinares (O'connell et al., 2009).

Dentro dos efeitos que a alteração no crescimento dos maxilares pode trazer está a má oclusão, a qual se situa no terceiro lugar entre as prioridades de saúde bucal na esfera da saúde pública; por sua alta prevalência, sendo que a cárie ocupa o primeiro lugar e as doenças periodontais o segundo (Frazão e Narvai, 2013).

Dentre as oclusopatias, as más oclusões severas e as incapacitantes, que requerem algum tipo de procedimento assistencial para reabilitação, correspondem a cerca de $10 \%$ a $20 \%$ dos casos, entre crianças em idade escolar no Brasil (Peres et al., 2013). Na Pesquisa Nacional de Saúde Bucal de 2003 (SB Brasil 2003), as más oclusões consideradas incapacitantes atingiram 20,8\% para o conjunto da população brasileira na idade-índice de 12 anos (Brasil, 2004).Na edição de 2010 da pesquisa 'SB Brasil', oclusopatias foram observadas em 38,8\% dos indivíduos de 12 anos de idade. Consta do relatório técnico da Pesquisa Nacional de Saúde Bucal - Brasil 2010, que as oclusopatias severas e muito 
severas correspondem a "condições que requerem tratamento mais imediato, constituindo-se em prioridade em termos de Saúde Pública” (Brasil, 2012).

A má oclusão tornou-se um distúrbio moderno, conforme as mudanças nos padrões comportamentais das populações da sociedade contemporânea, podendo gerar significativo impacto na qualidade de vida das pessoas. $\mathrm{Na}$ sociedade moderna, cresce a relevância da aparência. O sorriso faz parte fundamental da estética e da imagem de cada pessoa; com implicações psicológicas, podendo afetar os níveis de autoestima principalmente em escolares, mesmo na ausência de sintomas e com uma função em boas condições (Alvarez et al., 2010).

O propósito deste estudo foi conhecer os fatores associados ao crescimento transversal do osso maxilar, expresso pela distância intermolar superior; dado que as relações da distância intermolar superior com o peso ao nascer, o sexo, a idade de introdução da mamadeira e o estado nutricional (considerando o escore Z do IMC para a idade) não foram estudadas previamente; lacuna que esta pesquisa tenta preencher. 


\section{REVISÃO DA LITERATURA}

\subsection{O OSSO MAXILAR}

Conhecer a anatomia e a morfologia do osso maxilar é importante para entender os processos que intervêm em seu processo de crescimento. Nesta seção se faz uma aproximação aos principais elementos envolvidos no processo de crescimento e desenvolvimento do maxilar, abordados neste trabalho.

O maxilar é um osso que faz parte dos ossos faciais e está articulado quase com todos eles; localizando-se no terço médio da face. Este osso possui forma irregular que tende a ser um quadrilátero piramidal e contribui na conformação de estruturas anatômicas como a órbita ocular, os dois terços anteriores do palato na cavidade bucal, a cavidade nasal; e nele estão inseridos os dentes superiores.

Dentro de sua morfologia, existem quatro processos salientes ou apófises: o frontal (próximo à porção nasal do osso frontal, articulados pela sutura frontomaxilar), o zigomático (que está articulado ao osso zigomático por meio da sutura zigomaticomaxilar), o palatino (próximo aos ossos palatinos e conectados pela sutura palatina transversa; cuja parte inferior é parte do teto da cavidade bucal e cuja parte superior constitui o solo da cavidade nasal) e do processo alveolar (onde estão localizadas as raízes dos dentes superiores as quais estão separadas uma das outras pelos tabiques interalveolares e no caso de dentes multirradiculares, pelos tabiques interradiculares).

$\mathrm{Na}$ parte central interna do osso maxilar estão alojados os seios maxilares, duas cavidades pneumáticas cobertas de mucosa, por onde passa o ar inalado que é esquentado e umidificado em cada respiração. Os seios maxilares são os maiores de todos os seios paranasais, a saber, etmoidais, esfenoidais, nasais e maxilares, e são os primeiros a se desenvolver entre todos eles.

Ao momento do nascimento, cada um dos seios maxilares tem o tamanho de uma ervilha; e seu crescimento é determinado pelos dentes, pois a presença dos germes dentários dentro dos seios faz com que estes se desenvolvam após a 
erupção dentária e até a puberdade, momento em que adquirem seu tamanho médio. $\mathrm{Na}$ idade adulta, as raízes dos três molares permanentes chegam a entrar nos seios maxilares (Castellino et al., 1967). Daí a importância da sua análise prévia a qualquer tipo de cirurgia que envolva essa zona.

\subsubsection{Crescimento do maxilar}

Para o estudo mais detalhado do crescimento e desenvolvimento do osso maxilar, é necessário entender primeiro qual é a diferença entre esses dois termos.

A palavra crescimento está orientada para aquelas mudanças em aumento do tamanho e outras características físicas como forma, volume e peso. Portanto, o crescimento é suscetível de ser mensurado e pode ser descrito em unidades de medida. Segundo Moyers, o crescimento pode ser descrito como um aumento na quantidade de substância viva que diz respeito às mudanças nos aspectos quantitativos como o tamanho, a forma e a textura dos órgãos. O crescimento da pessoa, às vezes, pode implicar diminuição de algum órgão, como ocorre com o timo.

Por outro lado, o desenvolvimento dá conta das mudanças na estrutura do órgão; da sua diferenciação celular e tissular até ele adquirir certa complexidade com suas características morfológicas e funcionais próprias. É um conjunto de processos e mudanças que ocorrem até o indivíduo alcançar a vida adulta; e está composto por três partes: o crescimento, a diferenciação celular e a morfogênese (Moyers, 1979). Para medir o grau de desenvolvimento, são necessárias técnicas mais especificas e especializadas (Mayoral, 1977).

Os processos de crescimento e desenvolvimento no maxilar são complexos de explicar e diferentes, mas ocorrem de maneira simultânea. É possível encontrar grandes variações no crescimento, tanto geral quanto craniofacial, por conta dos fatores genéticos e ambientais envolvidos; conhecidos também como uma interação nature and nurture, respectivamente. Esses fatores estão em 
permanente interação e conjuntamente promovem as condições para que ocorra o processo de crescimento do complexo craniofacial (Frazão, 1999).

O crescimento facial pode ser estudado em três dimensões principalmente: vertical, transversal e anteroposterior. Estas dimensões estão sujeitas ao padrão de crescimento facial da pessoa, o qual depende do crescimento dos ossos faciais em conjunto, a base de crânio e a abóbada cranial, também chamada calvária. $O$ maxilar desempenha um papel chave no crescimento facial e no tipo de perfil facial. Dentro dos fatores principalmente envolvidos nesse padrão de crescimento facial está o crescimento das cavidades sinusais, a erupção dentária, o aumento da função muscular, entre outros.

O plano vertical é favorecido principalmente pelo aumento do tamanho do processo alveolar consequente da erupção dental, pelo crescimento do processo frontonasal, dos côndilos e dos seios maxilares, e pela respiração.

Para a dimensão transversal do crescimento facial, os principais elementos são a aposição nas paredes laterais do maxilar e a mandíbula, e o crescimento das apófises zigomática e alveolar.

Por outra parte, o crescimento no sentido anteroposterior é dado pelas suturas craniofaciais e pelo processo de aposição/reabsorção na tuberosidade e no borde posterior da rama ascendente da mandíbula. No maxilar o crescimento é descrito como aumento da largura (do tamanho) e ao mesmo tempo o deslocamento que ocorre em duas direções: vertical e anteroposterior (para frente e para baixo) (Castellino et al., 1967).

O crescimento do osso maxilar de uma criança acontece acompanhado de um processo de calcificação, da erupção dentária e da intervenção de forças musculares que promovem harmonicamente um desenvolvimento adequado (Mayoral et al., 1983). Esse tamanho alcançado pode ser estimado pela distância transversal do arco dental superior, através da medida da distância intermolar. 
Ao mesmo tempo ocorrem constantes mudanças na morfologia das estruturas ósseas, devidas a fatores externos ambientais e funções que desempenham os ossos e estruturas adjacentes.

Quando a criança tem entre 6 e 10 anos de idade, começa a ossificação intramembranosa no maxilar, fortalecendo o osso por meio desse processo que irá culminar em torno dos 10 anos, quando também se unirão os ossos da maxila com a pré-maxila até depois da puberdade (Belluzzo et al., 2012).

\subsubsection{Crescimento diminuído do maxilar}

Existem diversas causas que dão origem a alterações no crescimento de um órgão e podem, ao mesmo tempo, resultar em vários tipos de modificações desse órgão. O maxilar pode variar seu tamanho afetando qualquer das suas dimensões.

Quando ocorre um estreitamento do arco superior que causa diminuição da dimensão transversal do maxilar e palato estreito, diz-se que o maxilar é atrésico ou apresenta atrofia (Simões, 1985; Belluzzo et al., 2012). Nos casos em que o maxilar é anormalmente pequeno se denomina micrognatismo superior (Descritores em ciências da saúde).

Outros tipos de variações no tamanho do maxilar são a hipotrofia e a hipoplasia. Ambas indicam um maxilar de dimensões reduzidas, mas a diferença entre elas radica em que a hipotrofia se apresenta como a diminuição progressiva do maxilar consequente da redução do tamanho das células que o compõem. No entanto, seu crescimento foi atingido completamente (Langlais et al., 2011). Por outro lado, a hipoplasia maxilar é quando o maxilar exibe um tamanho reduzido por conta da diminuição do número de células que o constituem; indicando um desenvolvimento que não foi concluído (Stedman, 2012). A hipoplasia maxilar faz com que a mandíbula pareça maior, o palato estreito e fino, e existe mais probabilidade de possuir palato fendido (Raspall, 1997; Langlais et al., 2011).

No caso da atrofia do maxilar se manifesta uma redução de tamanho e/ou de número de células que fazem parte do osso maxilar (o qual tinha um 
desenvolvimento normal) e, portanto, leva à diminuição do seu volume, peso e função (Alves, 2004). A atrofia pode ser por causa do desgaste celular, morte ou reabsorção celular, proliferação celular diminuída, diminuição do volume celular, malnutrição, entre outras causas (Stedman, 2012).

No crescimento sob condições normais numa criança, certos aspectos são considerados para avaliar seu desenvolvimento na vida cotidiana. Elementos como a fala, a aparição dos dentes na boca, a alimentação, as respostas a estímulos, a estatura, o peso, etc. contam com parâmetros que determinam a normalidade ou indicam aos pais que a saúde do bebê está bem e que ele está se desenvolvendo adequadamente.

Mas existem algumas situações, em que esse crescimento normal é alterado por certo tipo de doenças, por exemplo, doenças próprias da infância precoce ou doenças febris. Segundo experiência clínica, Guardo menciona um grupo de doenças que podem alterar o crescimento maxilar e afetar a ordem cronológica da erupção dentária. Fazem parte desse grupo, doenças como os transtornos nutritivos do lactente, a poliomielite, a avitaminose, a anemia, a sífilis, a gastroenterocolitis, as doenças endócrinas, infecciosas e crônicas, entre outras (Guardo, 1981).

Como potenciais fatores associados às alterações no crescimento maxilar destacam-se traços genéticos (que também podem determinar a presença de síndromes craniofaciais), respiração bucal, diminuição nas funções orais, perdas prematuras de dentes temporários, paralisia facial infantil, atraso no início da alimentação complementar, hiper ou hipotonicidade muscular (nos músculos orbiculares da boca), hábitos de sucção não nutritiva, fonação e deglutição atípica e a posição anormal da língua (Guardo, 1981; Belluzzo et al., 2012).

Do ponto de vista do crescimento transversal do maxilar, existem algumas técnicas de mensuração formuladas na literatura que serão descritas a seguir. 


\subsubsection{Técnicas de mensuração transversal do maxilar}

São diversos os fatores que intervém no crescimento e desenvolvimento das estruturas orofaciais; tais como aquelas de tipo biológico, genético, social, funcional, ambiental etc. Existem diferentes técnicas de mensuração da dimensão transversal do maxilar cada uma com um índice próprio. Uma das mais conhecidas é o índice de Pont. Este índice foi desenvolvido por Pont na França em 1909 com indivíduos que tinham oclusão normal. O índice é utilizado na dentição permanente e é calculado em função da soma da largura mesodistal dos quatro incisivos superiores.

Mensura-se a distância existente entre os primeiros pré-molares desde o sulco fundamental; fazendo da mesma maneira com a distância intermolar, tomada desde a fossa central do sulco fundamental dos primeiros molares. Todas as medidas são calculadas em escala de milímetros $(\mathrm{mm})$; o índice também pode ser aplicado no arco dentário inferior, mas sempre fazendo uso da soma da largura mesodistal dos quatro incisivos superiores que, segundo Pont, deve ser de $35 \mathrm{~mm}$ idealmente. Em uma primeira parte, Pont propôs duas fórmulas para determinar o comprimento do arco dentário ideal: uma baseada na distância interpremolar e a outra na distância intermolar (Guardo, 1981; Carrizosa e Ortiz, 2003).

$$
\frac{\text { Soma das larguras dos incisivos superiores } * 100}{\text { Distância interpremolar }}=80
$$

$\mathrm{Na}$ fórmula anterior foi estabelecida a constante de 80 , cuja função é determinar a existência ou não de micrognatismo. Se o resultado for maior do que 80 o micrognatismo ou atresia será diagnosticado; mas se for menor haverá diastolia ou aumento transversal do maxilar. Em alguns artigos que utilizaram o índice de Pont, o resultado muda para 85 , pois se adotam as modificações feitas posteriormente por Linder-Harth. 
A segunda fórmula proposta por Pont faz uso da distância intermolar:

$$
\frac{\text { Soma das larguras dos incisivos superiores } * 100}{\text { Distânca intermolar }}=64
$$

$\mathrm{Na}$ fórmula anterior é usado 64 como constante de referência, mas tem autores que calculam o índice com 60 e outros com 65 . O que pode ser analisado é a variação do valor das constantes de referência que fazem alguns autores, mas é importante reconhecer que eles devem estabelecer escalas de medida próprias para chegar ao diagnóstico correto.

A confiabilidade do índice de Pont é posta em dúvida por alguns estudos feitos desde a sua criação, pois quando algumas comparações foram feitas em outras populações o índice pareceu estar sobreestimando as medidas das duas distâncias necessárias (interpremolar e intermolar). É possível que devido à realização do estudo de Pont em uma população francesa, o índice não seja aplicável em outras populações ou em outras etnias diferentes como demonstrado na Jordânia, em Paquistão e na Malásia (Al-Omari, 2007; Rathi e Fida, 2014; Alam et al., 2015).

O Professor alemão Korkhaus fez algumas modificações no índice de Pont agregando a dimensão de profundidade sagital (Guardo, 1981).

Bogue propôs uma medida para ser utilizada na dentição temporária para detectar o micrognatismo maxilar (atrofia) ou a determinação de um tamanho adequado do maxilar. $O$ índice tem uma importância significativa na literatura existente, mas tem variações nos diferentes artigos da área odontológica. Este índice está baseado em duas regras principais: a primeira regra estabelece uma distância intermolar mínima como parâmetro de diagnóstico precoce do micrognatismo transversal superior. A medida tem que ser tomada desde a superfície cérvico-palatina de cada segundo molar temporal e deve ser de $28 \mathrm{~mm}$ segundo alguns autores (Guardo, 1981) e $30 \mathrm{~mm}$ segundo outros (Mayoral et al., 1983). Caso a distância intermolar for menor se diagnostica micrognatismo 
maxilar; caso contrário se diagnosticará macrognatismo ou expansão aumentada do maxilar. Na segunda regra de Bogue considera-se como normais os diastemas presentes em dentes anteriores entre os 4 e os 5 anos de idade; caso esses diastemas não existam pode-se prever um possível apinhamento na futura dentição permanente daquela criança considerando a possibilidade de a criança ter macrodontia (o qual é muito pouco frequente na dentição temporária) combinada ou não com alguma alteração no crescimento transversal do maxilar sendo mais frequente o micrognatismo (Guardo, 1981). A medida pode ser tomada com um compasso ou elaborando um $T$ em fio ortodôntico que fácil e rapidamente é introduzida na boca ou colocada no modelo do paciente para medir essa distância (Guardo, 1981).

Em 1927, Izard sugeriu uma técnica para diagnosticar micrognatismo transversal em dentição tanto permanente quanto decídua que também recebe o nome de índice de arcada-face. Com ajuda de um compasso de espessuras se mede a distância compreendida entre os pontos mais distais dos arcos zigomáticos (distância bizigomática) imediatamente anterior ao tragus; e desta medida se restam $10 \mathrm{~mm}$ que segundo Izard corresponderiam aos tecidos faciais brandos, onde o interesse do índice é focalizado em tecidos duros. Com essa medida se estabelece uma relação com a largura do arco dentário superior, medida com o mesmo instrumento desde as superfícies vestibulares dos primeiros molares superiores. Em indivíduos sem alterações do crescimento facial e maxilar a medida do comprimento do arco dentário superior corresponde à metade da distância bizigomática (Guardo, 1981; Mayoral et al., 1983). A fórmula do índice arcada-face é a seguinte:

$$
\frac{\text { Largura máxima do arco } * 100}{\text { Largura bizigomática óssea máxima }}=50
$$


Como resultado é aceito uma variação de 48 a 52. Além deste índice, Izard apresentou o índice profundidade-arcada-face que leva em consideração a profundidade da face (Guardo, 1981).

O índice arcada-face pode ser complementado com as medidas interpremolares e intermolares propostas por Mayoral, pois há casos em que as proporções sugeridas por Izard são corretas, mas existe micrognatismo transversal devido a um menor crescimento das estruturas ósseas de uma forma proporcional; o resultado do índice também pode ser alterado pela morfologia cranial ou pelo tipo facial do paciente (Mayoral et al., 1983).

Em 1983, Mayoral propôs um índice para a dentição permanente que leva em consideração três medidas: (a) distância compreendida entre os sulcos centrais dos primeiros pré-molares superiores, que deve corresponder a $35 \mathrm{~mm}$; (b) distância compreendida entre os sulcos centrais dos segundos pré-molares superiores, que deve corresponder a $41 \mathrm{~mm}$; (c) distância compreendida entre as fossas centrais dos primeiros molares superiores, que deve corresponder a 47 $\mathrm{mm}$.

Se ao pegar tais medidas elas forem menores, será diagnosticado micrognatismo. As mensurações são realizadas com compasso de ponta fina (Mayoral et al., 1983).

Em 1920, Carrea se baseou em princípios geométricos através da formação de um triângulo para estabelecer relações nas arcadas para a análise transversal, análise de simetria dos arcos dentários e atresia (García et al., 2016). Consiste em dois índices realizados através de duas provas (prova $\mathrm{N}^{\circ} 1$ e prova $\mathrm{N}^{\circ} 2$ ). $\mathrm{Na}$ prova 1 devem ser somadas as larguras mesodistais dos incisivos (central e lateral), do canino, e dos pré-molares (primeiro e segundo), esperando-se ser igual à distância entre as fossas dos primeiros molares. Quando essa razão for maior do que 1 , o arco é estreito também chamado atresia; caso contrário é denominado diastolia (Guardo, 1981). 
Na prova 2 é usada a distância do ponto interincisivo e a fossa do primeiro molar, a qual deverá ser igual à distância bucodistal de canino a canino. Novamente quando o resultado dessa razão for maior do que 1 haverá atresia e provavelmente os incisivos estarão em lábio-versão ou a distância entre caninos será menor. Se essa relação for menor do que 1 haverá diastolia e possível linguoversão dos incisivos ou a distância entre os caninos estará aumentada (Guardo, 1981).

A linha perimétrica de Carrea trata da relação do perímetro do primeiro molar inferior permanente com a distância cervico lingual entre os primeiros molares superiores permanentes. Espera-se que sejam iguais nos casos de normalidade do arco dentário tanto transversal quanto longitudinalmente. Igualmente, Carrea estabeleceu uma linha perimétrica para a dentição decídua, pegando a medida do perímetro do segundo molar inferior (Guardo, 1981).

No caso da dentição decídua, o perímetro do segundo molar inferior corresponde à distância cervico lingual entre os segundos molares superiores. É conhecida como linha perimétrica infantil e é a base de um triângulo equilátero que é formado no arco dentário.

No maxilar superior, o vértice do triângulo é o ponto interincisivo e a base do triângulo é a distância cérvico lingual dos segundos molares superiores (distância média 27-30 mm) (Guardo, 1981). No maxilar inferior, a base do triângulo é o limite distal do arco dentário e o vértice é o ponto interincisivo inferior.

Estima-se que o tamanho dos arcos dentários poderá ser maior ou menor dependendo de fatores genéticos e também de certos estímulos ou circunstâncias aos quais a criança foi exposta; tais como alimentação, tipo de respiração, uso de mamadeiras e bicos, hábitos de sucção não nutritiva, entre outros. 


\subsection{PESO AO NASCER}

\subsubsection{Aspectos do peso ao nascer}

O peso ao nascer é considerado um importante indicador na área da saúde pública, que fornece informação referente a uma população determinada; englobando características tanto maternas quanto da criança. Poderá refletir circunstâncias prévias da mãe e alguns riscos futuros da criança como o desenvolvimento de doenças na vida adulta (UNICEF E OMS, 2004).

Segundo a Organização Mundial da Saúde, o baixo peso ao nascer se apresenta quando uma criança pesa menos de $2500 \mathrm{~g}$ no momento do nascimento. Estima-se que a cada ano cerca de 20 milhões de crianças nascem com baixo peso e aproximadamente $96 \%$ desses nascimentos ocorrem em países em desenvolvimento (OMS e UNICEF, 2004). A prevalência mundial de baixo peso ao nascer para 2010 foi de 10,55\% (Banco Mundial, 2017). No Brasil, para esse mesmo ano, a prevalência de crianças que nasceram com baixo peso foi de 8,39\% (Banco Mundial, 2017).

Realmente são muitas as situações que podem levar à condição de baixo peso ao nascer: tanto da mãe quanto da própria criança. Nos países em desenvolvimento é mais provável encontrar mães com desnutrição, precárias condições de saúde e que também devem trabalhar, pois muitas delas são mães solteiras (UNICEF, 2006). Analogamente, as principais causas do baixo peso ao nascer podem ser que a criança nasceu prematuramente ou que teve um crescimento intrauterino restrito (criança pequena para a idade gestacional) ou, crescimento intrauterino retardado (Marcondes et al., 2003).

No contexto da América Latina, segundo dados da UNICEF, a probabilidade de uma criança de baixos recursos econômicos ter baixo peso ao nascer é 3,6 vezes maior comparado a uma criança com uma situação econômica mais favorável (UNICEF, 2006).

O baixo peso ao nascer é conhecido por ser um fator de risco importante para morbimortalidade no período perinatal e de mortalidade no primeiro ano de vida; 
aumentando assim a frequência de diarreia e de doenças respiratórias, problemas comuns em crianças recém-nascidas (OMS e UNICEF, 2004). Portanto, torna-se ainda mais vital proporcionar à criança o devido aleitamento materno exclusivo por seis meses se é que a criança é capaz de mamar. O aleitamento artificial será considerado apenas nos casos em que a criança ainda não possui aqueles reflexos que permitem retirar o leite do peito da mãe.

Vários estudos têm mostrado a relação do baixo peso ao nascer com problemas de desenvolvimento na infância e transtornos de saúde na idade adulta (Ponce et al., 1994; Druet e Ong, 2008; O'connell et al., 2009; Khadilkar et al., 2015; Berglund et al., 2016).

\subsubsection{Peso ao nascer e a cavidade bucal}

Existem poucas publicações investigando os efeitos na cavidade bucal decorrentes do baixo peso ao nascer. Em 1979, Garn et.al pesquisaram a influência de fatores pré-natais nas dimensões da coroa dentária (nas medidas tanto mesodistal quanto bucolingual).

Além do baixo peso ao nascer, analisaram características da mãe que predispõem um menor tamanho dentário. Apontaram que o diâmetro dentário

diminui quando há hipertensão materna, baixo peso ao nascer ou quando a criança é pequena para a idade gestacional (Garn et al., 1979).

Em 1993, Fearne e Brook, fizeram um estudo de caso e controle com os modelos em gesso de 72 crianças de raça branca com peso menor a $2000 \mathrm{~g}$ de aproximadamente sete anos de idade. Os resultados evidenciaram menor tamanho mesodistal no grupo com baixo peso ao nascer sugerindo que o menor período de tempo de crescimento na fase pré-natal pode gerar consequências para o desenvolvimento nos períodos peri e pós-natal sem desconsiderar que 0 tamanho da coroa dentária depende tanto de fatores genéticos quanto ambientais (Fearne e Brook, 1993). 
Posteriormente, Seow et. al em 2005, a partir de uma amostra de 90 incisivos centrais superiores decíduos esfoliados, avaliaram a qualidade do esmalte dentário concluíndo que nas crianças que nasceram com muito baixo peso (peso menor a $1500 \mathrm{~g}$ ) o esmalte dentário era de menor qualidade e as dimensões dos dentes eram também menores, possivelmente resultante do crescimento pré-natal reduzido (Seow et al., 2005). Enquanto maior maturidade pulmonar tem sido observada no sexo feminino, maior peso ao nascer e risco aumentado de mortalidade neonatal e infantil e de parto prematuro tem sido notado entre os homens (Ghosh et al., 2007). 


\subsection{ALEITAMENTO DA CRIANÇA}

A nutrição é um elemento fundamental no crescimento geral da criança e determina em grande parte a saúde na infância e na vida adulta. O aleitamento é uma fase importante da alimentação e é primordial para promover uma vida saudável na criança e uma melhor qualidade de vida.

\subsubsection{Tipos de aleitamento}

Existem principalmente dois tipos de aleitamento: o natural (a partir de leite materno/humano) e o artificial (com leite de vaca ou de fórmula). O aleitamento materno pode ser exclusivo, quando a criança recebe só leite materno (seja ordenhado ou diretamente do peito) ou leite humano. Também pode ser aleitamento materno predominante, quando a criança ingere além do leite materno, bebidas a base de água como sucos ou chás. No aleitamento complementado a criança se alimenta de leite materno e este é complementado com alimentos sólidos e semisólidos. No aleitamento materno a criança recebe principalmente leite materno ou humano e leites artificiais ou de vaca (Brasil, 2009a; OMS, 2009).

Em que pesem algumas controvérsias, reconhece-se na literatura científica importantes diferenças do ponto de vista funcional e nutricional entre o aleitamento natural e o artificial (OPS e OMS, 1972; Zöllner e Jorge, 2005; Brasil, 2009a; Knoll, 2016). A força que deve ser exercida pelos músculos buco-maxilo-faciais ao igual que os músculos que estão envolvidos nos processos de sucção e deglutição variam de um tipo de aleitamento para o outro (Inoue et al., 1995; Gomes et al., 2006).

As diferenças presentes entre os tipos de aleitamento, não só se evidenciam nas funções de estruturas ósseas e musculares, mas também no aporte nutricional. O leite materno fornece os nutrientes adequados nas proporções adequadas para a criança e é de fácil digestão para a criança (Brasil, 2009a).

$\mathrm{Na}$ literatura cientifica existem inúmeras pesquisas sobre a importância do aleitamento materno para a saúde e sobrevivência das crianças, pois o 
aleitamento materno diminui a mortalidade infantil e evita a aparição de várias doenças como diarréia, alergias, reduz a chance de desenvolver obesidade, diabetes, hipertensão ou infecções respiratórias (Brasil, 2009b; Sankar et al., 2015; Victora et al., 2016).

São inegáveis as diversas vantagens que se fornecem à criança através do aleitamento materno natural; como funcionais, imunológicos, psicológicos e nutricionais, para mencionar algumas delas. Além disso, o aleitamento faz com que a sociedade se torne mais equitativa e mais saudável por ser a medida de maior eficácia e mais baixo custo envolvida na alimentação da criança; e favorece tanto a saúde da criança quanto a saúde da mãe (Brasil, 2009b; Victora et al., 2016). A partir desta etapa vão se criando hábitos de nutrição saudável, e, ao mesmo tempo se previne a instalação de hábitos de sucção não nutritiva $\mathrm{e}$ consequente má oclusão (Almeida, 1999; Knoll, 2016).

No início da vida, toda criança tem o direito a ser amamentada e toda mãe tem direito a amamentar. Existem programas que buscam a proteção da amamentação como um ato natural e necessário, que pode se realizar em diferentes espaços com liberdade e sem preconceito. Recomenda-se que a primeira mamada ocorra na primeira meia hora de vida e que o leite dos primeiros quatro dias, também conhecido como colostro, tem importantíssimo aporte nutricional e imunológico à criança (OMS, 2003).

Segundo as recomendações da Organização Mundial da Saúde (OMS) e o Fundo das Nações Unidas para a Infância (UNICEF) toda criança deve receber exclusivamente leite materno até os seis meses de idade (OMS, 2003). Nesses primeiros anos de vida, a criança só precisa do leite materno como fonte de alimento. Não é preciso fornecer água, sucos, chá, leites em pó ou leite de fórmula; pois os leites alternativos não são comparáveis com o valor nutricional do leite materno, que não pode ser igualado por leites industrializados ou pelo leite de vaca (Zöllner e Jorge, 2005; Brasil, 2009a).

$\mathrm{Na}$ atualidade as mães têm à disposição diversos tipos de leite e diversas opiniões dos médicos pediatras e nutricionistas que apoiam o uso de leites 
diferentes ao materno. É importante saber que o uso de outros tipos de leite não representa um benefício real para a criança.

Sobre esse aspecto, ressalta-se a necessidade de abordar este tema e aprofundar o conhecimento prévio e as sugestões da literatura que indicam uma possível associação entre o aleitamento materno e as estruturas buco-maxilofaciais (Zöllner e Jorge, 2005; Maia-Nader et al., 2014; Peres et al., 2015).

Manifestam-se aqui outras situações relativas também à Saúde Pública como a diminuição da desnutrição em menores de 5 anos através da amamentação, da morbidade e da mortalidade, e de problemas afetivos e psicológicos futuros. Por representar uma ajuda para a economia familiar e promover a pronta recuperação da mãe após o parto, entre outras razões, organizações internacionais unem esforços a favor do aleitamento materno como medida de promoção de saúde. Exemplo disso é a Estratégia Global de Alimentação de Lactentes e Crianças de Primeira Infância da OMS, que foi adotada em 2002 pelos Estados Membros da OMS e a Junta Executiva da UNICEF com a finalidade de promover melhores condições de alimentação em crianças (OMS, 2003). O estabelecimento por parte da UNICEF de diretrizes para os serviços de maternidade são essenciais, por exemplo os Dêz passos para o sucesso do aleitamento materno; cujo cumprimento deriva em inúmeros benefícios para as famílias. $O$ dever dos centros de saúde que atendem mães e crianças são encargados de entregar estas informações às famílias, assim como defender o aleitamento natural evitando a promoção de leites industrializados ou de bicos e chupos (OMS e UNICEF, 1989).

\subsubsection{O tipo de aleitamento e a cavidade bucal}

Os estudos desenvolvidos no marco do aleitamento materno ou do tipo de alimentação oferecida para a criança e seus efeitos no sistema estomatognático refletem alguma controvérsia e aspectos que merecem melhor elucidação.

Zöllner et. al em 2005 concluíram que crianças aleitadas ao peito apresentam menos problemas de saúde, consequências favoráveis imunológicas e do ponto de vista estomatognático, terão condições de exercer as "funções orais perfeitas" 
e, portanto, podendo com isso ser prevenidos problemas ortodônticos e ortopédicos (Zöllner e Jorge, 2005). Numa revisão da literatura, verificou-se que desmame precoce e uso de mamadeira podem afetar o reflexo natural da sucçãodeglutição podendo produzir má oclusão. Menor duração da amamentação exclusiva e maior frequência de má oclusão foi uma associação encontrada também em vários estudos (Almeida et al., 2005).

Assim, a má oclusão pode ser considerada um distúrbio presente nas sociedades industrializadas, pois um processo tão natural como a amamentação, se torna permeabilizado pelo mercado através da indústria dos leites artificiais, os bicos e mamadeiras; que contribuem ao desmame precoce e causando má oclusão (Almeida, 1999; Corrêa et al., 2016). As mudanças no ambiente e nas formas de viver nas cidades promovem novas maneiras de levar a vida que acabam modificando nossas características biológicas. Essas interações se refletem também na cavidade bucal de populações atuais, onde as necessidades e as exigências funcionais são absolutamente diferentes aos tempos quando devíamos caçar os alimentos e garantir a nossa sobrevivência. Estudos antropológicos mostram que pesadas exigências no sistema mastigatório não são características dos habitantes das cidades modernas. Não surpreende, portanto, que as dentições de muitas populações hodiernas, comparadas àquelas de seus ancestrais, que eram caçadores e juntavam alimentos de forma nômade, denotem evidência de reduzida função e eficiência mastigatória, juntamente com uma crescente prevalência de oclusopatias (Frazão, 1999).

Revisão da literatura constatou uma redução do risco de má oclusão quando as crianças são amamentadas, atribuindo à duração e à exclusividade do aleitamento materno, importante peso para o desenvolvimento harmonioso da oclusão (Peres, 2015). Santos Neto et al. fizeram um estudo longitudinal com crianças examinadas até os 36 meses de idade; concluindo que a amamentação é um fator importante no crescimento craniofacial e que o uso de mamadeira restringe o crescimento do arco dental superior e favorece a ocorrência de mordida aberta anterior. Os autores ressaltam que os efeitos da mamadeira são 
visíveis nos arcos superior e inferior. A idade de introdução e de término do uso da mamadeira, além da duração do seu uso, mostra-se determinantes no desenvolvimento da oclusão (Santos-Neto, 2012).

Em 2010, Sánchez et al. baseados em análises cefalométricas em crianças de 6 a 11 anos, acharam que o aleitamento materno ajuda no adequado desenvolvimento orofacial; observando protrusão dos incisivos superiores nas crianças alimentadas com mamadeira e relações vertical e sagital mais favoráveis com respeito à base do crânio no grupo amamentado. Diferenças esqueléticas, dentais e estéticas entre crianças alimentadas ao peito e com mamadeira foram apreciadas; sugerindo uma associação com hábitos orais deletérios (SánchezMolins, 2010).

Em uma revisão divulgada em 2013, Narbutyte conclui que o aleitamento materno diminui a presença de anomalias dento alveolares, principalmente de mordida cruzada posterior. Os autores indicam que ainda não é possível afirmar que existam modificações esqueléticas devidas ao uso de mamadeira, por conta da insuficiente informação disponível (Narbutyte, 2013).

Outros autores também concordam na importância da amamentação na prevenção de hábitos deletérios e no desenvolvimento mais harmônico das funções e das estruturas do sistema estomatognático; e por tanto, possibilitando uma oclusão mais apropriada (Gama et al., 1997; Zöllner e Jorge, 2005; Salone et al., 2013; Knoll, 2016). 


\subsection{ESTADO NUTRICIONAL}

O estado nutricional é uma condição resultante da composição da alimentação (tipo e quantidade dos alimentos ingeridos), das necessidades do organismo em energia e nutrientes, e da eficiência do aproveitamento biológico dos alimentos, ou seja, da nutrição propriamente dita (Cardoso, 2014). A avaliação do estado nutricional pode ter por foco tanto indivíduos, geralmente aplicada para auxiliar a clínica médica, quanto populações, situação em que é usada como um importante indicador de saúde coletiva.

Os dados antropométricos como o peso e a estatura da criança são medidas que fornecem informação valiosa ao respeito do estado nutricional e do crescimento da criança e se este é adequado para a idade. Tanto o peso quanto a estatura apresentam diferenças segundo o sexo da criança.

A Organização Mundial da Saúde desenvolveu padrões e curvas de crescimento para lactentes e crianças discriminados por sexo e por idade desde 0 nascimento até os 5 anos. Dada a importância destes indicadores do estado nutricional, é indispensável tomar todos os cuidados e seguir os protocolos no momento da mensuração. De igual maneira, a idade deverá ser calculada de forma exata com meses ou semanas completas se a criança for menor de um ano; se for maior, se calcula em anos e meses completos (OMS, 2008).

O indicador do comprimento para a idade é utilizado em crianças de 0 a 24 meses e sua mensuração se realiza com a criança deitada; o indicador da estatura para a idade para crianças de 2 a 5 anos, a medida é tomada com a criança em pé. Estes dois indicadores manifestam o crescimento linear da criança para sua idade e permite identificar crianças com retraso no crescimento por aporte insuficiente de nutrientes ou doenças recorrentes, quando o índice é baixo. No caso de altos índices de estatura para idade deve-se avaliar se a criança tem problemas endócrinos pouco comuns (OMS, 2008). 
Com respeito ao peso da criança o primeiro indicador é o peso ao nascer, medido em gramas; pode revelar aspectos do estado de saúde e nutricional tanto da mãe quanto da criança.

O indicador do peso para a idade não é utilizado para diagnosticar sobrepeso ou obesidade, mas para identificar crianças com baixo peso ou baixo peso severo. É indispensável considerar a idade da criança, uma vez que o baixo peso pode indicar não somente desnutrição, mas também uma baixa estatura (OMS, 2008).

Como consta nas tabelas de peso para a idade e de estatura para a idade da OMS; para uma menina de 5 anos no percentil da mediana o peso deve estar em torno de $18,2 \mathrm{~kg}$ e a estatura em torno de $109,4 \mathrm{~cm}$, para um menino o peso deveria ser ao redor de $18,3 \mathrm{~kg}$ e a estatura de 110,0 $\mathrm{cm}$ (Child growth standards, OMS). Considerando que neste estudo as medidas foram tomadas quando as crianças tinham em torno de 5 anos.

O índice de massa corporal (IMC), também conhecido como índice de Quetelet por seu criador Adolphe Quetelet, é obtido a partir do peso do indivíduo em quilogramas dividido pela estatura em metros elevada ao quadrado.

Em crianças de 0 a 5 anos de idade, o IMC é calculado com base na idade da criança; sendo que a idade deve ser estimada sob os mesmos critérios que nos indicadores anteriormente mencionados. O IMC para a idade é de muita utilidade na identificação precoce de sobrepeso ou obesidade nas crianças. As curvas convencionadas pela OMS dividem este indicador para duas faixas etárias; de 0 a 2 anos e de 2 a 5 anos; existe também a curva que define o IMC de 0 a 5 anos. $O$ ajuste por idade se dá uma vez que as crianças têm um ganho de peso rápido e expressivo (OMS, 2008). Segundo as tabelas da OMS, para a idade de 5 anos o IMC deve estar em torno de 15,3 e 15,2 para meninas e meninos, respectivamente (Child growth standards, OMS).

A partir do IMC é possível obter o escore Z do IMC para a idade. Este define, em termos de desvios padrão, o quanto se afastam as medidas de uma criança da mediana para essa população nessa mesma idade. 


\section{OBJETIVOS}

\subsection{Objetivo geral}

Identificar possíveis associações entre a distância intermolar superior e características ligadas ao curso da vida da criança.

\subsection{Objetivos específicos}

3.2.1. Analisar o efeito que tem o sexo sobre a distância intermolar superior.

3.2.2. Analisar o efeito do peso ao nascer sobre a distância intermolar superior.

3.2.3. Analisar o efeito da idade de introdução da mamadeira sobre a distância intermolar superior.

3.2.4. Analisar o efeito do escore $Z$ do IMC para a idade sobre a distância intermolar superior.

3.2.5. Analisar as relações entre as variáveis independentes consideradas no estudo.

3.2.6. Indicar possíveis implicações para a saúde materna e infantil a partir dos resultados obtidos. 


\section{MÉTODOS}

\subsection{Desenho do estudo}

Trata-se de um estudo transversal aninhado numa coorte de base populacional no município de Acrelândia, no estado de Acre, Brasil; que faz parte da Amazônia Ocidental Brasileira. O município é o menor do estado e tem uma localização fronteiriça que limita a leste com Bolívia, com o município de Senador Guiomard ao oeste, com os estados de Amazonas e Rondônia ao norte, e com o município de Plácido de Castro (Acre) ao sul e sudoeste. A atividade econômica de maior desempenho no município de Acrelândia é a agropecuária e a indústria madeireira.

Figura 1. Localização do município de Acrelândia no Brasil.

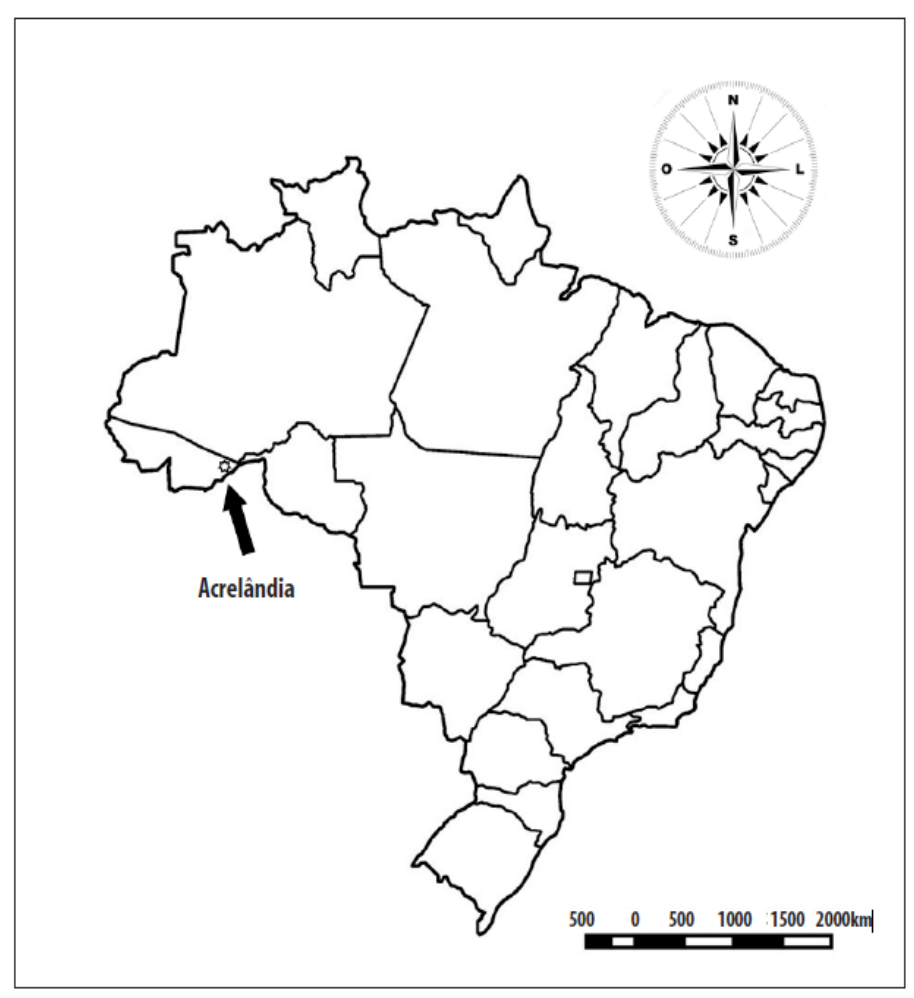

Fonte: (Frazão et al., 2016)

Segundo o Censo demográfico realizado pelo Instituto Brasileiro de Geografia e Estatística (IBGE) em 2010, a população de Acrelândia era de 12.538 
habitantes das quais, 5.216 moravam na zona urbana, conformando um 47,2\%. Em 2003, data em que se iniciou a coorte do presente estudo, a população de Acrelândia era de 8.697; dos quais 43\% morava na zona urbana (Lourenço et al., 2015).

Segundo as informações fornecidas pelo Instituto Brasileiro de Geografia e Estatística (IBGE) e o Atlas de Desenvolvimento Humano no Brasil, em 1991 o índice de desenvolvimento humano (IDH) para o município foi de 0,247, em 2000 foi de 0,451 e em 2010 foi de 0,604. Para o estado de Acre em 1991 o IDH foi de 0,402; em 2000 foi de 0,517 e em 2010 foi de 0,663. O índice de desenvolvimento humano no Brasil é de 0,754 (IBGE; PNUD, INSTITUTO DE PESQUISA ECONÔMICA APLICADA E FUNDAÇÃO JOÃO PINHEIRO).

\subsection{População do estudo}

A investigação tem por base um estudo longitudinal mais amplo sobre saúde e condições nutricionais realizado pela Universidade de São Paulo em parceria com a Universidade Federal do Acre- UFAC (Muniz et al., 2007).

A coorte teve início com um estudo transversal de base populacional em 2003 com a colaboração das equipes locais do "Programa Saúde da Família" do Ministério de Saúde do Brasil, em base nas informações censitárias de 2002 fornecidas pelas equipes (Muniz et al., 2007). Foram convidados a participar da pesquisa todas as famílias da zona urbana de Acrelândia, 334 domicílios que tinham crianças menores de 5 anos de idade, dos quais 2 domicílios recusaram participar. Resultaram 332 domicílios (99,4\%) com 489 crianças; das quais 467 (95,5\%) foram incluídas no estudo de 2003 (Lourenço et al., 2015).

De 14 a 31 de janeiro de 2003 realizaram-se entrevistas face a face com as mães ou cuidadores das crianças nos domicílios com a cooperação dos agentes comunitários de saúde, estudantes de enfermagem da Universidade Federal do Acre e profissionais da saúde com supervisão da equipe de pesquisadores (Muniz et al., 2007). 
As entrevistas foram realizadas por entrevistadores de campo devidamente capacitados, que previamente solicitaram aos entrevistados sua autorização por meio de assinatura do Termo de Consentimento Livre e Esclarecido (Anexo 1), assegurando confidencialidade da informação dada e dos resultados individuais. Foram explicados os objetivos do estudo e os benefícios da sua participação. As informações coletadas na entrevista se relacionavam com características demográficas, socioeconômicas, maternas, nutricionais e de morbidade da criança.

Novamente em 2007 foi feito um censo nos domicílios com crianças menores de 10 anos, e que incluiu 250 crianças das 467 examinadas em 2003. Tomaram-se medidas antropométricas referentes a peso e estatura das crianças (Cardoso et al., 2012; Lourenço et al., 2015).

Em dezembro de 2009 um terceiro estudo transversal foi efetuado com 205 crianças que haviam sido examinadas também em 2003 e 2007 (Cardoso et al., 2012; Lourenço et al., 2015).

Depois, em 2010, um novo estudo transversal foi realizado sob a coordenação do Prof. Paulo Capel Narvai (Processo CNPq 402260/2008-2). Foram realizados exames odontológicos nas crianças de escolas localizadas na área urbana que tivessem entre 7 e 9 anos de idade (203 crianças correspondendo a 85.5\% das crianças avaliadas em 2007). Em 2010 os exames dentários foram feitos em todas as crianças por um único examinador. O estudo foi aprovado pelo Comitê de Ética em Pesquisa da Faculdade de Saúde Pública da Universidade de São Paulo mediante o protocolo 297/2009 (Anexo 2) (Frazão et al., 2014a; Frazão et al., 2016).

$\mathrm{Na}$ Figura 2 mostra-se o fluxograma da amostragem desde 2003, ano do início da coorte, até 2010; e o tamanho final da amostra que conformou este estudo. A taxa de retenção conseguida na amostra foi de $32,3 \%$. 
Figura 2. Fluxograma de amostragem. Acrelândia, Amazônia Ocidental Brasileira, 2010.

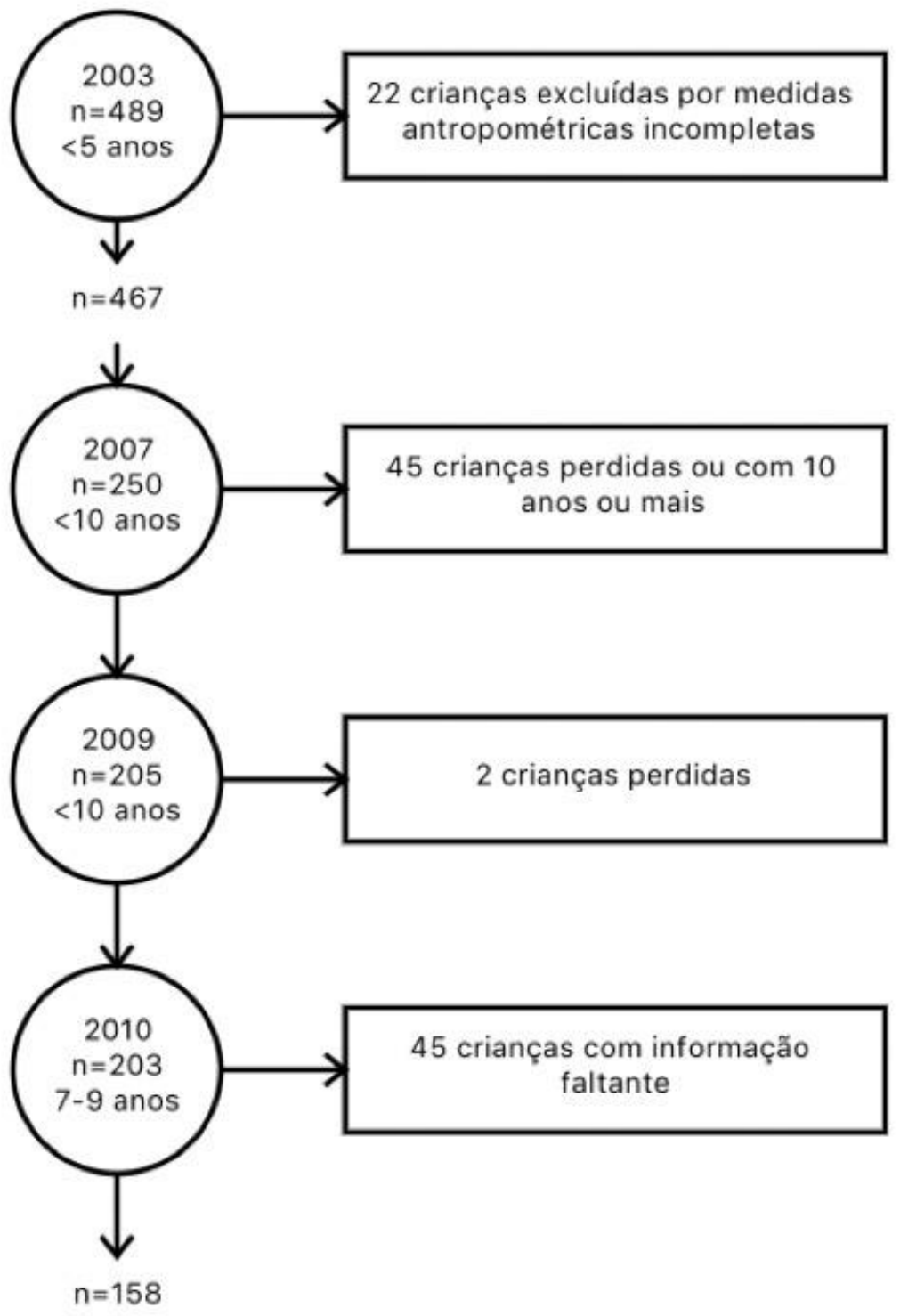

\subsection{Variáveis do estudo}

A variável dependente foi representada pela distância intermolar no maxilar dada em milímetros $(\mathrm{mm})$, admitindo-se que ela pode operar como um indicador do grau de crescimento do osso maxilar em sua dimensão transversal (Alvaran et al., 2009). 
As variáveis independentes foram aquelas relacionadas com características da criança (sexo, peso ao nascer e escore $Z$ do IMC para a idade) e com o padrão de uso da mamadeira operacionalizado por meio de uma escala correspondente a idade de introdução da mamadeira.

O peso ao nascer foi tomado em 2003 do cartão de saúde da criança. Outra variável considerada no estudo é a idade de introdução da mamadeira em dias. A partir dos dados obtidos foi construída uma variável correspondente a uma escala que permitiu analisar o tempo de duração do aleitamento materno exclusivo e o uso da mamadeira; fornecendo assim informação sobre a estimulação orofacial que a criança teve na infância precoce.

A idade de introdução da mamadeira foi coletada em 2003. A partir desta variável foi desenvolvida uma escala para avaliar o padrão de uso da mamadeira elaborado com base na distribuição por decis de idade de introdução em dias, a fim de assumir como mínimo o valor 1 para o caso de nunca haver sido introduzida a mamadeira (crianças que tiveram apenas o aleitamento materno exclusivo) e como máximo o valor 10. Portanto, foram considerados períodos de tempo mais curtos do que em outras pesquisas que avaliaram o uso de mamadeira. Em outros estudos que consideraram a duração do aleitamento com mamadeira, os períodos de tempo foram de 0 a 6 meses, de 6 a 18 meses e mais de 18 meses (Chen, 2015); outro estudo avaliou o período de uso de mamadeira por menos de um ano, de 12 a 23 meses e por 2 anos ou mais (Maia-Nader, 2014). Estudos com intervalos mais curtos, avaliaram a introdução do leite de vaca como inferior ou superior a 3 meses de idade (Cardoso et al., 2012; Lourenço et al., 2012; Lourenço et al., 2015).

$\mathrm{Na}$ construção da escala, foram combinadas faixas etárias utilizadas e descritas na literatura científica e em documentos da OMS, e uma distribuição relativamente homogênea em torno de intervalos de valores por decis da distribuição; conforme a Figura 3. Observando-se que a variável de introdução da mamadeira foi coletada em dias, isso permitiu classificar as crianças em períodos 
de tempo mais curtos nos valores mais altos da escala do padrão de uso da mamadeira.

Na Figura 3 são mostrados os valores atribuídos segundo a distribuição da idade de introdução da mamadeira na escala elaborada.

Figura 3. Escala do padrão de uso da mamadeira elaborada a partir da idade de introdução da mamadeira para crianças de 7 a 9 anos na Amazônia Ocidental Brasileira.

\begin{tabular}{|c|c|c|}
\hline Idade de introdução da mamadeira & $\mathbf{n}(\%)$ & Valor na escala \\
\hline Nunca usou & $29(18,35)$ & 1 \\
$>12$ meses & $17(10,76)$ & 2 \\
$>9-\mid 12$ meses & $10(6,33)$ & 3 \\
$>6-\mid 9$ meses & $14(8,86)$ & 4 \\
$>4-\mid 6$ meses & $19(12,03)$ & 5 \\
$>3-\mid 4$ meses & $9(5,70)$ & 6 \\
$>2-\mid 3$ meses & $16(10,13)$ & 7 \\
$>1$ - 2 meses & $14(8,86)$ & 8 \\
15 dias a 1 mês & $17(10,76)$ & 9 \\
0 a 14 dias & $13(8,23)$ & 10 \\
\hline
\end{tabular}

Foi considerada também a variável escore $Z$ do IMC para a idade entre 4 e 6 anos, conforme sugerido pela OMS (Onis et al., 2007). As medidas de peso e altura foram obtidas por pessoas treinadas, por meio de procedimentos padronizados, utilizando equipes devidamente calibradas e repetindo uma vez cada medida e calculando a média das duas mensurações. A altura foi definida com um estadiômetro (model 208; SECA, Hamburg, Germany) com o valor de 0,1 $\mathrm{cm}$ mais próximo. As crianças descalças se colocaram em posição de pé no meio do estadiômetro com a cabeça, os ombros, as nádegas e os calcanhares 
encostando a parede. O peso mediu-se com balança eletrônica (model HS-302; Tanita, Tokyo, Japan), tomando o valor que ficasse mais próximo correspondente a $100 \mathrm{~g}$ (Cardoso et al., 2012).

\subsection{Coleta dos dados}

Em 2010, exames dentários foram realizados por um único dentista devidamente calibrado. Sob condições de iluminação natural e utilizando um compasso de ponta seca (drypoint caliper) e um paquímetro digital (digimatic caliper) da marca Mitutoyo e precisão de $+/-0,02 \mathrm{~mm}$, mediu-se a distância intermolar em milímetros, tomando como pontos de referência as fossas centrais dos primeiros molares superiores permanentes direito e esquerdo nas 158 crianças; como foi proposto e descrito por Mayoral em 1983 (Mayoral et al., 1983) e adotado por Alvaran et al em 2009 (Alvaran et al., 2009).

\subsection{Controle das observações}

Além da medida oclusal direta, para controlar as observações e aferir sua consistência foram obtidas impressões das arcadas dentárias numa subamostra de 38 crianças. A subamostra foi conformada por crianças que apresentavam todos os dentes caninos decíduos e todos os primeiros molares permanentes em condições de higidez. Dos 203 participantes, 19 foram excluídos devido à impossibilidade de registro da distancia intermolar e sinal de respiração bucal.

Para as impressões foram empregadas moldeiras plásticas pré-fabricadas de diferentes tamanhos e um material à base de alginato do Tipo II, com presa normal, consistência média, propriedades físicas, características tixotrópicas, escoamento e elasticidade que permitem a reprodução de detalhes de até $50 \mu$. Para a confecção dos modelos de estudo foi usado gesso pedra tipo III. Medidores padronizados também foram utilizados para as medidas de pó e água, atendendo as especificações do fabricante tanto para o hidrocolóide quanto para o gesso, no intuito de reduzir alterações dimensionais e otimizar as qualidades mecânicas e estabilidade dos moldes e modelos. Em 2010, a examinadora também foi 
calibrada para medir o pó e a água para confecção dos modelos em gesso pedra tipo III. Para essa calibração utilizou-se balança de precisão do Laboratório de Saúde Pública do Departamento de Prática de Saúde Pública da FSP da USP. Também foram obtidas mordidas em cera rosa № 7 na posição de máxima intercuspidação dos arcos dentários. Foi adotada a seguinte técnica: uma moldeira plástica autoclavável, devidamente esterilizada, adequada ao tamanho e forma da arcada foi selecionada, observando-se o comprimento e a largura de forma que todos os elementos dentários e os tecidos moles circunvizinhos fossem incluídos. Após a seleção, preparou-se a moldeira, com uma tira de cera plástica ou "utility" ou cera "Utilidade" de aproximadamente $5 \mathrm{~mm}$ de largura fixando-a às bordas da moldeira em todo seu contorno superior, com o cuidado de não bloquear as áreas de retenção dessa moldeira. Em seguida, a cera foi cortada de modo que fossem feitos alívios nas áreas referentes aos freios e bridas, obtendose assim, um contorno adequado da anatomia do fundo do vestíbulo ou do assoalho bucal. Na moldeira superior, uma tira de $1 \mathrm{~cm}$ foi colocada na porção do palato, com o objetivo de reduzir a distância entre a moldeira e o palato, assegurando uma espessura uniforme de aproximadamente 5 a $7 \mathrm{~mm}$.

Os valores das medidas lineares diretas e indiretas relativas à distância intermolar foram comparadas por teste de correlação e o coeficiente de correlação de Pearson foi elevado $(r=0,806)$. O valor utilizado neste estudo corresponde à medida direta.

\subsection{Análise dos dados}

A análise descritiva dos dados foi realizada com o programa Stata/SE 13.1. Numa primeira etapa foi feita a análise descritiva das variáveis do estudo, apurando-se os valores da média, mediana e desvios padrão das variáveis e a forma de sua distribuição na amostra estudada com ajuda de histogramas.

Para fazer o teste de aderência à curva normal da variável dependente foi aplicado o teste de Kolmogorov-Smirnov esperando-se um nível descritivo maior do que 0,05 . 
A comparação de médias entre os valores da distância intermolar, do peso ao nascer e do escore $Z$ do IMC para a idade entre os dois sexos, foi realizada com teste $\mathrm{t}$ de Student. Para comparar as médias dos valores da distância intermolar entre as idades das crianças foi realizada uma análise de variância (ANOVA). Todos os testes tiveram como nível descritivo 0,05.

As análises estatísticas dos dados foram realizadas utilizando análise de caminhos no marco de um modelo de equações estruturais (MEE) por meio do programa Mplus 7 (Muthén \& Muthén, 2012). O estimador de Máxima Verossimilhança Robusta (MLR) foi obtido para analisar as relações estruturais, correspondentes às associações entre variáveis. O nível descritivo das associações foi fixado em 0,05 .

Este procedimento permite fazer uma análise a partir de um modelo teórico, na qual são consideradas diversas equações de regressão em um único modelo. Uma variável é definida como uma variável de desfecho em uma relação e como variável explicativa em outra relação. Um exemplo disso é a variável do padrão de uso da mamadeira; que se apresenta como variável resposta para a variável do peso ao nascer, e por outro lado, se apresenta como variável explicativa da distância intermolar. A Figura 4 mostra o modelo teórico que foi testado considerando algumas relações descritas na literatura e algumas hipóteses não descritas. As relações entre sexo e peso ao nascer (Barros et al., 1996; Boshari et al., 2013), a associação do sexo e o estado nutricional (Lourenço et al., 2015), a relação do sexo e a oclusão (Siriwat e Jarabak, 1985; Baccetti et al., 2005) e do sexo com a erupção dentária (Rousset et al., 2001; Rousset et al., 2003; Jogahara e Natori, 2012), os efeitos do peso ao nascer no estado nutricional (Lourenço et al., 2015; Zhu et al., 2015), o vínculo do aleitamento e a cavidade bucal (MaiaNader et al., 2014; Chen et al., 2015; Peres et al., 2015) e entre o aleitamento e o estado nutricional (Baker et al., 2004), as relações entre peso ao nascer e a erupção dentária e a oclusão são efeitos que ainda não foram explorados na literatura, do peso ao nascer no uso da mamadeira (Zhu et al., 2015), e por último, os possíveis efeitos do estado nutricional na oclusão (Frazão et al., 2014b). 
O estudo dessas múltiplas relações permite estabelecer várias hipóteses onde estaria presente uma associação dessas variáveis com o crescimento do osso maxilar. Em primeiro lugar espera-se que, como em estudos anteriores, os meninos apresentem em média um maior peso ao nascer do que as meninas (Peabody et al., 1998). Crianças que tiveram um maior peso ao nascer poderiam apresentar uma melhor condição nutricional durante a infância em comparação com as crianças com peso ao nascer reduzido. Estudos que encontraram dimorfismo sexual para algumas dimensões craniofaciais verticais, permitem hipotetizar que esse dimorfismo sexual também pode se manifestar no crescimento transversal do maxilar (Baccetti, 2005; Siriwat, 1985). Crianças com baixo peso ao nascer têm coroas dentárias menores além de esmalte de pobre qualidade (Fearne e Brook, 1993; Garn, 1979; Seow, 2005). Isso pode resultar na hipótese de que crianças de menor peso ao nascer, têm potencial para apresentar maxilar com dimensões reduzidas.

A hipótese que sustenta uma associação entre a idade de introdução da mamadeira e o crescimento transversal do maxilar teve por fundamento os estudos que têm produzido evidências de que o uso da mamadeira é nocivo para o desenvolvimento e a função das estruturas buco-maxilo-faciais (Viggiano et al., 2004; Sánchez-Molins, 2010; Carrascoza, 2006). Além de prejudicar a duração do aleitamento materno exclusivo, contribui ao desmame precoce e induz a criança a formar hábitos de sucção não nutritiva por meio de bicos e chupetas (não sendo o único causante). Estes acabam favorecendo as mudanças na morfologia dos ossos faciais, alterando também as relações entre maxilares e dentes, dando lugar aos desvios de oclusão (como mordida aberta anterior e palato atrésico). Por outro lado, a alimentação ideal para uma criança menor de dois anos é o aleitamento materno. Aquelas crianças que fizeram uso da mamadeira em idades muito precoces podem ter desenvolvido deficiências nutricionais e de crescimento ósseo geral com manifestações na cavidade bucal implicando um espaço reduzido nos maxilares para a erupção dentária. Diante desse quadro, investigou-se uma possível associação entre a idade de introdução da mamadeira e a distância intermolar superior como estimadora do crescimento transversal do maxilar. 
O ajuste do modelo de equações estruturais foi realizado através do teste de qui-quadrado, que indica discrepância entre os valores da amostra e os valores estimados (valor de referência>0,05); índice de ajuste comparativo (CFI) que leva em consideração a complexidade do modelo, e representa uma medida comparativa global entre o modelo estimado e o modelo nulo (que assume que todas as variáveis latentes não estão correlacionadas). São desejáveis valores de 0,95 ou mais (valor de referência>0,95). O índice de Tucker Lewis (TLI) contempla a complexidade do modelo e seu uso é similar ao índice de ajuste normalizado. São desejáveis valores acima de 0,95 (valor de referência>0,95). Outro indicador é a raiz da média dos quadrados dos erros de aproximação (RMSEA). Essa medida leva em consideração o tamanho da amostra, analisando o quanto 0 modelo se ajusta à população e não apenas à amostra estudada refletindo um valor que corresponde à falta de ajuste por graus de liberdade (valor de referência $<0,05)$. 
Figura 4. Modelo teórico dos diversos caminhos que foram testados entre as variáveis independentes e a associação com a distância intermolar.

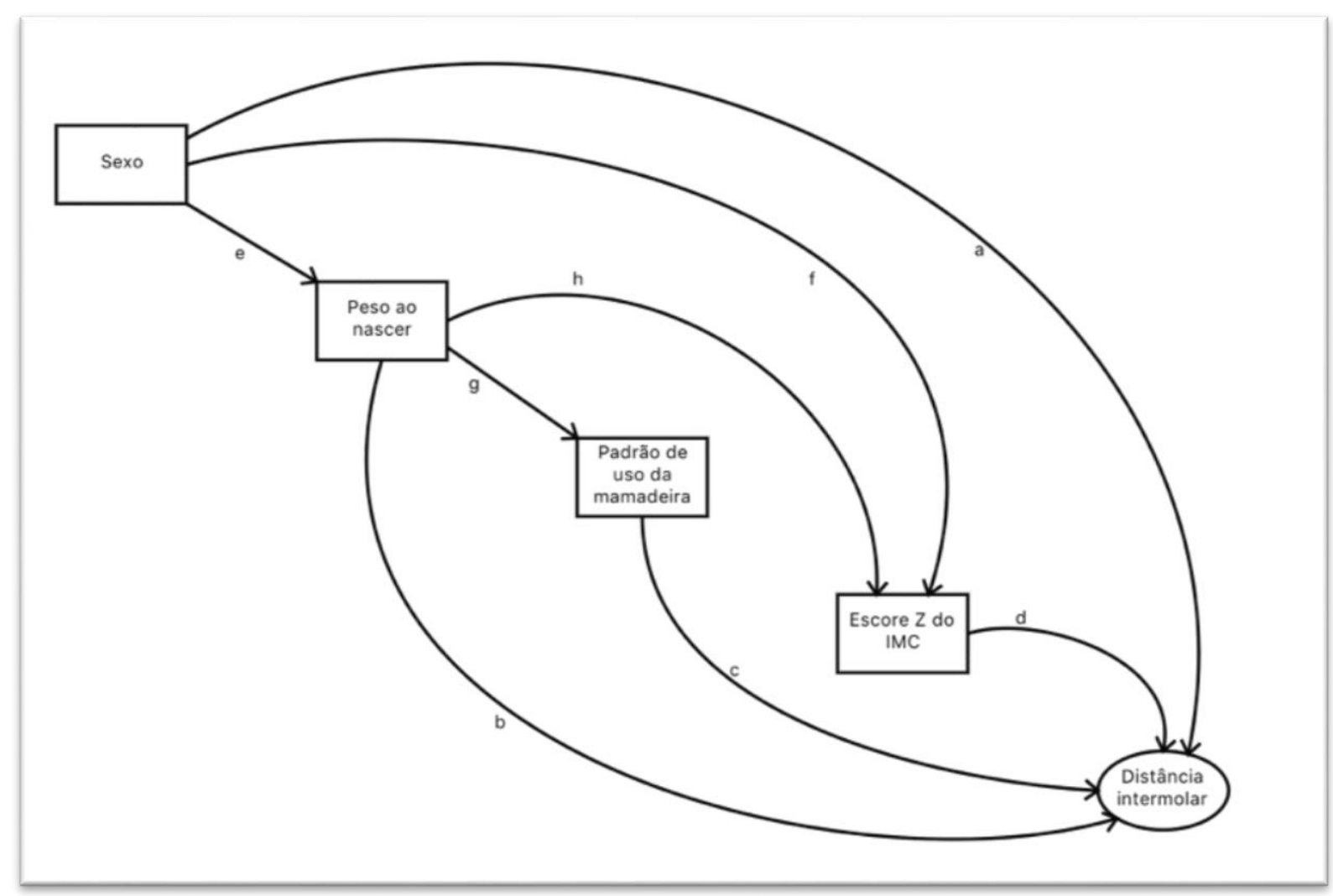

a. Siriwat e Jarabak, 1985; Baccetti at al., 2005; Rousset et al., 2001; Rousset et al., 2003; Jogohara e Natori, 2012. b. Garn et al., 1979; Fearne e Brook, 1993; Seow et al, 2005. c. MaiaNader et al., 2014; Chen et al., 2015; Peres et al., 2015. d. Frazão et al., 2014. e. Barros et al., 1996; Boshari et al., 2013. f. Lourenço et al., 2015. g. Zhu et al., 2015. h. Lourenço et al., 2015; Zhu et al., 2015. 


\section{RESULTADOS}

\subsection{Caracterização da amostra}

A amostra final foi conformada por 158 crianças entre 7 e 9 anos de idade, das quais 73 eram do sexo masculino (53,8\%) e 85 do sexo feminino $(46,2 \%)$. A distribuição da idade na amostra foi dada por 48 crianças de 7 anos $(30,4 \%), 62$ crianças de 8 anos $(39,2 \%)$ e 48 crianças de 9 anos (30,4\%).

A Tabela 1 mostra a distribuição das frequências das variáveis na amostra e o coeficiente de correlação de cada variável em relação à distância intermolar; aparecem em negrito aqueles valores que tiveram significância estatística (valor de $p<0,05)$. A variável do escore $Z$ do índice de massa corporal para a idade foi a única variável com dados faltantes (apenas duas observações).

Foi encontrada uma proporção de $8,86 \%(n=14)$ de crianças com baixo peso ao nascer. Das quais $10(71,4 \%)$ eram do sexo feminino.

Tabela 1. Estatística descritiva das variáveis do estudo em crianças de 7 a 9 anos de idade. Acrelândia, Amazônia Ocidental Brasileira, 2010.

\begin{tabular}{|c|c|c|c|c|c|c|}
\hline Variável & $\mathbf{n}$ & Média (DP) & Mediana & Min-Max & $\mathbf{r}$ & Valor $p$ \\
\hline Distância intermolar (mm) & 158 & $45,38(2,97)$ & 45,56 & 31,$71 ; 53,43$ & - & - \\
\hline Sexo & 158 & - & - & - & 0,27 & 0,0005 \\
\hline Peso ao nascer (g) & 158 & $3.326,65(642,03)$ & $3.335,00$ & $1.200,00 ; 4.730,00$ & 0,23 & 0,0044 \\
\hline $\begin{array}{l}\text { Padrão de uso da } \\
\text { mamadeira }\end{array}$ & 158 & $5,09(3,06)$ & 5,00 & 1,$00 ; 10,00$ & $\begin{array}{c}- \\
0,16\end{array}$ & 0,0514 \\
\hline Escore Z do IMC & 156 & $-0,04(0,99)$ & $-0,14$ & $-2,43 ; 3,09$ & 0,24 & 0,0025 \\
\hline
\end{tabular}

O valor médio do peso ao nascer dos meninos $(3.490,75 \mathrm{~g})$ foi maior do que o das meninas (3.185,72 g) e a diferença foi estatisticamente significativa $(p=0,0026)$. $O$ coeficiente $\beta$ de regressão entre o peso ao nascer e o sexo, foi de 
305,04; indicando que o peso ao nascer nos homens é, em média, maior por 305 g quando comparado com o peso ao nascer no sexo feminino $(p=0,0026)$.

O valor médio do escore $Z$ do IMC para a idade entre os meninos foi $0,12 \mathrm{e}$ entre as meninas $-0,18$ com uma diferença estatística marginal $(p=0,0565)$.

A distância intermolar mostrou aderência à curva de normalidade $(p=0,625)$. Ao comparar as médias dos valores da distância intermolar entre os dois sexos, encontrou-se uma diferença estatisticamente $(p=0,0005)$; sendo que a média nos meninos foi $46,25 \mathrm{~mm}$ e nas meninas foi $44,63 \mathrm{~mm}$. Comparando as diferenças entre as médias dos valores da distância intermolar entre as idades das crianças (7, 8 e 9 anos) verificaram-se diferenças estatisticamente não significativas $(p=0,086)$.

\subsection{Modelo estrutural}

No MEE foram observadas diversas relações entre as variáveis, tanto diretas quanto indiretas. A Figura 5 mostra o modelo obtido com os respectivos valores dos coeficientes padronizados para a distância intermolar superior.

O ajuste do modelo mostrou índices satisfatórios: Valor $\mathrm{p}$ do qui-quadrado $(p=0,4817)$; CFI $(1,000)$; TLI $(1,064)$; RMSEA $(0,0000)$. 
Figura 5. Modelo de equações estruturais para a distância intermolar superior de crianças entre 7 e 9 anos de idade. Acrelândia, Amazônia Ocidental Brasileira. 2010 .

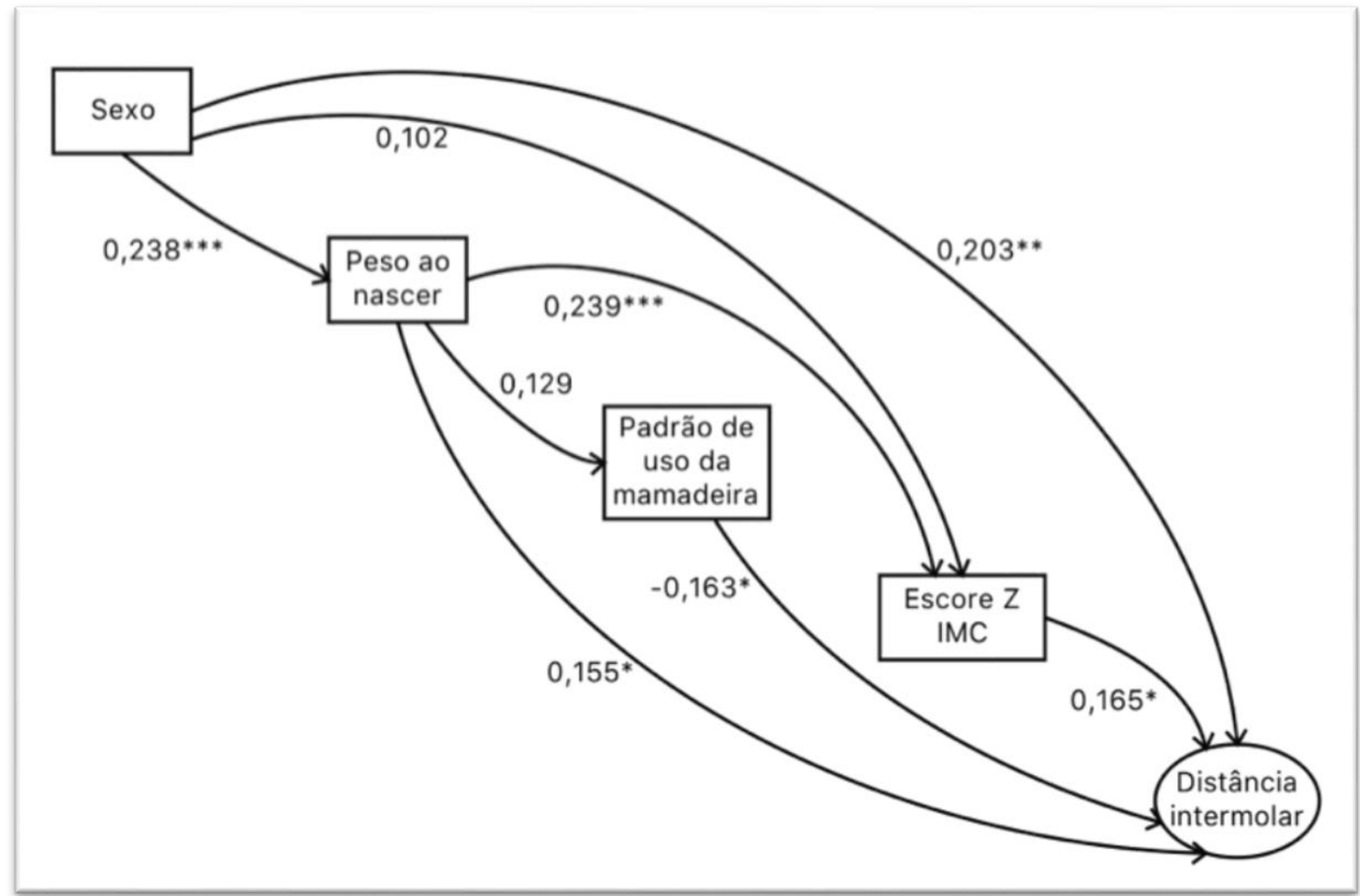

Nível de significância

${ }^{*}<0,05$

$* *<0,01$

$* * *<0,005$

\subsection{Efeitos diretos das variáveis independentes sobre o desfecho}

As quatro variáveis independentes consideradas no estudo (sexo, peso ao nascer, padrão de uso da mamadeira e escore $Z$ do IMC para a idade) apresentaram associação direta e significativa com a distância intermolar superior. Todas as variáveis, com exceção do padrão de uso da mamadeira, apresentaram correlação positiva com o desfecho.

A soma dos efeitos diretos e indiretos do sexo sobre o desfecho (efeito total) foram significativos $(\mathrm{CP}=0,262 ; \mathrm{p}=0,000)$. $\mathrm{O}$ efeito direto positivo do sexo 
sobre a distância intermolar reflete que os meninos apresentaram maiores valores desta medida, indicando, portanto um maior crescimento transversal do osso maxilar neste grupo $(C P=0,203 ; p=0,007) . O$ coeficiente $\beta$ de regressão entre a distância intermolar e o sexo, foi de 1,627; indicando que a distância molar nos homens é, em média, maior por 1,627 mm quando comparado com a distância intermolar no sexo feminino $(p=0,0005)$. Ao realizar o teste t para comparar as médias dos valores da distância intermolar entre os sexos observou-se uma diferença estatisticamente significativa entre eles $(p=0,0005)$.

A variável sexo apresentou o coeficiente de maior magnitude $(C P=0,203)$, embora muito próximo aos das demais variáveis na associação com o desfecho, de forma a serem iguais para efeitos práticos. As associações diretas encontradas com a distância intermolar são apresentadas na Tabela 2.

O efeito direto positivo do peso ao nascer sobre o desfecho indica que quanto maior for o peso ao nascer da criança, maior será a distância intermolar superior $(C P=0,155 ; p=0,046)$. De igual maneira, quanto maior for o escore $Z$ do IMC para a idade, maior será a medida da distância intermolar superior $(\mathrm{CP}=0,165 ; \mathrm{p}=0,030)$.

A variável do padrão de uso da mamadeira mostrou ter um efeito direto negativo sobre o desfecho. Dado que esta variável atribui um valor de 1 a 10 (onde 1 é para quem nunca usou mamadeira e 10 para quem começou a usar mamadeira entre os 0 e os 14 dias de idade); quer dizer que quanto mais cedo foi introduzida a mamadeira, menor foi o valor observado para a distância intermolar superior $(C P=-0,163 ; p=0,027)$. 
Tabela 2. Efeitos diretos observados sobre a distância intermolar superior em crianças de 7 a 9 anos de idade. Acrelândia, Amazônia Ocidental Brasileira, 2010.

\begin{tabular}{lcc}
\hline Variável & Coeficiente4 & Valor de $\mathbf{p}$ \\
\hline Sexo & 0,203 & $0,007^{\star}$ \\
Peso ao nascer & 0,155 & $0,046^{*}$ \\
Padrão de uso da mamadeira & $-0,163$ & $0,027^{\star}$ \\
Escore Z IMC para a idade & 0,165 & $0,030^{\star}$ \\
\hline
\end{tabular}

${ }^{*}$ Valores estatisticamente significativos para um valor $p<0,05$

\subsection{Efeitos indiretos das variáveis independentes sobre o desfecho}

Os efeitos indiretos produzidos pelas variáveis sobre o desfecho podem ser vistos através de diversos caminhos de interação entre as variáveis independentes ou explicativas (Tabela 3). Cada variável tem um efeito direto e um ou mais efeitos indiretos sobre a distância intermolar.

Iniciando com o sexo, que é variável mais distal com respeito à distância intermolar, observou-se o efeito direto e quatro caminhos que contribuem nos efeitos indiretos dessa variável sobre o objeto de estudo. Como apresentado anteriormente, $o$ efeito direto foi significativo $(C P=0,203 ; p=0,007)$. $O$ conjunto dos quatro efeitos indiretos também foi significativo $(\mathrm{CP}=0,058 ; \mathrm{p}=0,029)$. No entanto, ao analisar cada efeito indireto separadamente é observado que nenhum deles foi significativo.

Tabela 3. Efeitos indiretos da variável sexo sobre a distância intermolar em crianças de 7 a 9 anos de idade. Acrelândia, Amazônia Ocidental Brasileira, 2010.

\begin{tabular}{lcc}
\hline Caminho analisado & Coeficiente & Valor de $\mathbf{p}$ \\
\hline Sexo $\rightarrow$ escore Z do IMC $\rightarrow$ distância intermolar & 0,017 & 0,266 \\
Sexo $\rightarrow$ peso ao nascer $\rightarrow$ distância intermolar & 0,037 & 0,093 \\
Sexo $\rightarrow$ peso ao nascer $\rightarrow$ escore Z do IMC $\rightarrow$ distância intermolar & 0,009 & 0,125 \\
Sexo $\rightarrow$ peso ao nascer $\rightarrow$ mamadeira $\rightarrow$ distância intermolar & $-0,005$ & 0,227 \\
\hline
\end{tabular}


Quanto aos efeitos do peso ao nascer, além do efeito direto, foram encontrados dois caminhos pelos quais se observam efeitos indiretos. Como apresentado anteriormente o efeito direto do peso ao nascer sobre a distância intermolar foi estatisticamente significativo $(\mathrm{CP}=0,155 ; \mathrm{p}=0,046)$. Os efeitos indiretos em conjunto $(C P=0,018 ; p=0,508)$ ou de cada caminho separadamente (Tabela 4), não mostraram significância estatística, porém o efeito total do peso ao nascer sobre o desfecho (ou seja, a somatória dos efeitos direto e indiretos) foi estatisticamente significativo $(\mathrm{CP}=0,174, \mathrm{p}=0,023)$.

Tabela 4. Efeitos indiretos da variável peso ao nascer sobre a distância intermolar em crianças de 7 a 9 anos de idade. Acrelândia, Amazônia Ocidental Brasileira, 2010.

\begin{tabular}{lcc}
\hline Caminho analisado & Coeficiente & Valor de $\mathbf{p}$ \\
\hline Peso ao nascer $\rightarrow$ escore $Z$ do IMC $\rightarrow$ distância intermolar & 0,039 & 0,078 \\
Peso ao nascer $\rightarrow$ mamadeira $\rightarrow$ distância intermolar & $-0,021$ & 0,190 \\
\hline
\end{tabular}

\subsection{Associações entre variáveis independentes}

No presente estudo, as variáveis sexo, peso ao nascer, padrão de uso da mamadeira e escore $Z$ do IMC interagem entre elas e essas associações podem ser analisadas no MEE. As associações que foram objeto de análise estão na Tabela 5. Observaram-se duas associações significativas: o sexo associado ao peso ao nascer e o peso ao nascer associado ao escore $Z$ do IMC para a idade.

Tabela 5. Análise de associações entre variáveis independentes entre crianças de 7 a 9 anos de idade. Acrelândia, Amazônia Ocidental Brasileira, 2010.

\begin{tabular}{lcc}
\hline Associação & Coeficiente & Valor de $\mathbf{p}$ \\
\hline Sexo $\rightarrow$ escore Z do IMC & 0,102 & 0,194 \\
Sexo $\rightarrow$ peso ao nascer & 0,238 & $0,002^{*}$ \\
Peso ao nascer $\rightarrow$ escore Z do IMC & 0,239 & $0,002^{*}$ \\
Peso ao nascer $\rightarrow$ padrão de uso da mamadeira & 0,129 & 0,099 \\
\hline
\end{tabular}

*Valores estatisticamente significativos para um valor $p<0,05$ 


\section{DISCUSSÃO}

A média da distância intermolar na amostra foi de $45,38 \mathrm{~mm}$; levemente baixa em comparação com a observada por Alvaran et al. com a mesma técnica de mensuração em crianças entre 7,9 e 10,2 anos de idade (46,9 mm) (Alvaran et al., 2009). A taxa de retenção observada na amostra se deve ao longo período de acompanhamento que implicou o estudo.

A proporção observada de crianças com baixo peso ao nascer na amostra foi de $8,9 \%$, semelhante à descrita para a coorte que deu origem ao presente estudo (Lourenço et al., 2015), e compatível com as estimativas de prevalência de baixo peso ao nascer no Brasil, 7,8\% em 2009, 8,4\% em 2010 e 9,0\% em 2011 (Banco Mundial, 2017).

\section{Efeitos diretos sobre o desfecho}

O efeito do sexo sobre a distância intermolar teve um efeito total significativo com maiores valores para os meninos. Estes resultados são compatíveis com os obtidos por Aznar e colaboradores a partir de um estudo transversal em uma amostra de 1.297 crianças de 3 a 6 anos de idade na Espanha. Seus resultados apontaram a distâncias canina e intermolar -tanto em maxilar quanto em mandíbula- significativamente maiores nos meninos. Entretanto, hipóteses para explicar isto não foram levantadas (Aznar et al., 2006).

Alguns estudos prévios asseguram que existem diferenças entre meninas e meninos na oclusão devido ao dimorfismo sexual existente nos parâmetros craniofaciais (Siriwat e Jarabak, 1985; Baccetti et al., 2005). Examinando 1.094 cefalometrias de indivíduos com má oclusão classe III, pesquisadores identificaram, que entre 7 e 9 anos de idade, as meninas apresentavam dimensões lineares de maxilar, mandíbula e altura facial significativamente menores comparando com as medidas dos meninos (Baccetti et al., 2005). 
Visto que o sexo foi a variável com o coeficiente padronizado de maior valor, pode se pensar que sua influência sobre o crescimento transversal do maxilar, é de uma magnitude importante. A hipótese que foi apresentada no presente trabalho da relação existente entre sexo e crescimento transversal do maxilar, devida parcialmente ao dimorfismo sexual e às diferenças que este define, foi confirmada.

Ao analisar os valores da distância intermolar por idade, não houve diferenças significativas. Acredita-se que as diferenças observadas nas medidas da distância intermolar não são devidas à idade, mas ao sexo e a outros fatores que poderiam intervir nessa correlação.

Conhecer e monitorar o peso ao nascer é importante para evitar riscos de morbimortalidade neonatal e infantil. No entanto, a relação do peso ao nascer e o crescimento transversal do maxilar ainda não tinha sido explorada. Nos efeitos do peso ao nascer sobre o desfecho, observou-se que o peso ao nascer mostrou significância só e também na presença de outras variáveis, sugerindo que o peso ao nascer exerce influência sobre o crescimento transversal do maxilar.

Até o presente estudo, a única relação descrita na literatura científica se referia ao tamanho diminuído das coroas dentais em crianças que nasceram com baixo peso (Garn et al., 1979; Fearne e Brook, 1993; Seow et al., 2005). Partindo dessa informação, e ponderando os resultados obtidos neste estudo os resultados sugerem que valores mais baixos de peso ao nascer na presença de outros fatores, podem favorecer valores mais baixos de distância intermolar afetando crescimento transversal do maxilar confirmando-se a hipótese estabelecida neste estudo.

Excetuando-se o padrão de uso da mamadeira que apresentou efeito negativo, todas as variáveis apresentaram efeito positivo sobre o desfecho. Isso indica que quanto mais precocemente for introduzida a mamadeira, menor será a distância intermolar superior. Nenhum estudo prévio investigou essa relação específica entre a idade de introdução da mamadeira e o crescimento transversal do osso maxilar. 
O uso da mamadeira não representa só uma mudança nutricional, mas também funcional. No estudo feito por Inoue e colaboradores, foram realizadas provas de eletromiografia comparando a atividade do músculo masseter de 12 crianças alimentadas ao peito e 12 crianças alimentadas por mamadeira enquanto elas estavam se alimentando. Os resultados mostraram uma atividade significativamente reduzida nas crianças que usavam mamadeira; e sugerem que como consequência dessa baixa atividade muscular, os maxilares podem apresentar uma redução de tamanho (Inoue et al., 1995).

Em estudo similar, Gomes e colaboradores compararam a atividade muscular dos músculos masseter, temporal e buccinador entre crianças amamentadas e crianças alimentadas com mamadeira. $O$ resultado foi contundente ao revelar a atividade significativamente maior em crianças aleitadas ao peito. Eles relatam que o aleitamento materno fornece o estímulo adequado para o desenvolvimento das estruturas orofaciais, o tônus muscular, a articulação temporomandibular e um espaço adequado para a erupção dentária. Tais características poderiam explicar o papel da dimensão transversal do maxilar, ainda que parcialmente na associação negativa desta com o padrão de uso da mamadeira encontrada no presente trabalho, dado que existe um desequilíbrio no tonus muscular nas crianças que iniciaram precocemente o uso de mamadeira (Gomes et al., 2006).

No estudo de Peres e colaboradores, foi concluído que o aleitamento materno diminui o risco de apresentar má oclusão. Há uma diferença na sucção realizada em crianças amamentadas quando comparada com crianças alimentadas com mamadeira. É reiterada a alta atividade muscular durante 0 aleitamento materno, o que possibilita o crescimento apropriado craniofacial, incluíndo os maxilares (Peres et al., 2015).

Pode-se admitir que na relação do padrão de uso da mamadeira com a distância intermolar superior existem variáveis não contempladas neste estudo que poderiam estar mediando esse caminho. Como por exemplo a atividade funcional dos músculos envolvidos nos processos de respiração, mastigação, 
sucção e deglutição. Além disso, uma criança que usa mamadeira por mais tempo (desde uma idade mais precoce), terá maior probabilidade de desmame precoce e de desenvolver hábitos de sucção não nutritiva. Maia-Nader e colaboradores estudaram uma amostra de 1.463 crianças entre 7 e 11 anos de idade e encontraram que o aleitamento com mamadeira por dois anos ou mais, é um fator de risco para os hábitos prolongados de sucção não nutritiva. $O$ alimento levado pela mamadeira pode saciar a fome, mas não supre a necessidade de sucção do bebê, favorecendo a aquisição de hábitos de sucção não nutritiva com uso da chupeta, do dedo, e de outros bicos e objetos (Maia-Nader et al., 2014). A consequência é o desenvolvimento de oclusopatias, como a mordida aberta anterior e a atrofia do maxilar superior com importante impacto no desalinhamento dentário (Carrascoza et al., 2006; Maia-Nader et al., 2014).

Embora um estudo tenha identificado uma associação significativa entre baixa estatura para a idade e apinhamento dentário entre adolescentes com histórico prolongado de respiração bucal (Thomaz et al., 2010), o caminho pelo qual o escore $Z$ do IMC para idade, tem um efeito direto sobre a distância intermolar não foi ainda explorado na literatura científica, e os resultados apresentados são um aporte significativo nas evidências empíricas que fundamentam as bases teóricas relacionadas ao crescimento transversal do osso maxilar.

\section{Efeitos indiretos sobre o desfecho}

Além do efeito direto do sexo sobre a distância intermolar superior, foram encontrados quatro efeitos indiretos no modelo estrutural que em conjunto apresentaram significância estatística. Isto mostra que o crescimento no maxilar depende de múltiplos fatores que intervêm nesse processo, além da influência genética que sempre está envolvida.

Os resultados relativos ao modo como o peso ao nascer influencia o crescimento transversal do maxilar indicam que as manifestações sobre 0 
desfecho dependem de uma ação combinada decorrente do tipo de aleitamento e de várias características da criança.

\section{Associações entre as variáveis independentes}

Usualmente, existem diferenças no peso ao nascer entre os dois sexos, segundo informes da Organização Mundial da Saúde (OMS) e do Fundo das Nações Unidas para a Infância (UNICEF). No momento do nascimento, as meninas pesam menos do que os meninos com a mesma idade gestacional (UNICEF E OMS, 2004).

Vários estudos corroboram essa relação entre o sexo do recem nascido e o peso ao nascer (Mondal, 1998; Barbieri et al., 2000; Castaño-Castrillón et al., 2008; Voldner et al., 2009; Huerta e Salgado, 2012). No presente estudo os meninos apresentaram uma média de peso ao nascer maior quando comparados com as meninas; houve uma diferença de $305,35 \mathrm{~g}$ entre o sexo feminino e o sexo masculino. Em estudo com 522 recém-nascidos, Voldner e colaboradores constataram que os meninos pesaram $184 \mathrm{~g}$ mais do que as meninas (Voldner et al., 2009). Peabody e colaboradores encontraram que meninos pesaram em média $181 \mathrm{~g}$ mais do que as meninas no momento do nascimento (Peabody et al., 1998).

Os resultados deste estudo corroboram essa diferença nos resultados conseguidos, confirmando a hipótese aventada. O peso ao nascer nas meninas tende a ser menor, consequentemente, o sexo feminino tem maior risco de nascer com baixo peso em relação ao sexo masculino (Ghosh et al., 2007). Além do sexo do bebê, existem circuntâncias genéticas e ambientais que irão determinar o peso ao nascer. As condições da mãe podem produzir alterações no peso ao nascer da criança (Nascimento et al., 2017).

Quanto à relação do sexo com o estado nutricional, foram encontrados vários estudos que sustentam esta relação, indicando que o sexo masculino tem um melhor estado nutricional o que se traduz em um maior escore $Z$ do IMC para 
a idade; no entanto, essa correlação não foi significativa neste estudo. Em estudo a partir da coorte que deu origem à presente investigação, os resultados mostraram uma associação positiva entre o escore $Z$ do IMC para a idade e 0 sexo masculino entre os 6 meses e os 7 anos de idade. Também foi referido que os valores do escore z para IMC dos meninos ficavam próximos da mediana, enquanto os valores das meninas sempre foram mais baixos. Até um ano de idade e aos 7 anos, o escore $z$ do IMC foi significativamente maior nos meninos. A prevalência de magreza ou baixo peso corporal foi maior em meninas (Lourenço et al., 2015).

A literatura estabelece que o peso ao nascer de uma criança pode ser um dos determinantes do seu estado nutricional futuro, o qual pode ser estimado por meio de indicadores antropométricos como o utilizado neste estudo: o escore $z$ do IMC para a idade. No estudo de Lourenço e colaboradores, foi referida também uma correlação positiva entre o peso ao nascer e o escore $Z$ do IMC para a idade durante a infância (Lourenço et al., 2015).

Neste estudo foram identificadas e analisadas, de modo original, relações que não foram antes estudadas. Embora uma associação não significativa entre peso ao nascer e a idade de introdução da mamadeira tenha sido observada, há estudos que estabelecem certo caminho que pode chegar a vinculá-los. Uma pesquisa encontrou associações positivas diretas entre o peso ao nascer e todas as medidas antropométricas avaliadas incluindo o escore $Z$ do IMC. Efeitos diretos e indiretos foram observados entre peso ao nascer, duração do aleitamento materno, idade de introdução de alimentos sólidos e o escore Z do IMC (Zhu et al., 2015).

As linhas de investigação científica de maior interesse relacionadas aos problemas oclusais têm sido o estudo das características crânio-faciais em indivíduos e alguns poucos grupos populacionais, e o estudo dos efeitos da terapia ortodôntica/ortopédica em pacientes (Frazão, 1999), sendo comparativamente muito pequena a produção de estudos epidemiológicos que 
permitam extrair implicações para a saúde materna e infantil. Neste contexto, são raros os estudos que utilizaram a distância intermolar superior como um desfecho epidemiológico e os resultados apresentados no presente estudo relativo aos caminhos e aos efeitos e associações de algumas variáveis sobre esse desfecho descortinam uma linha investigativa promissora a todos os interessados em explorar de forma mais aprofundada potenciais fatores de proteção e de risco associados ao crescimento transversal do maxilar; com por exemplo aspectos genéticos e outros ligados à alimentação complementar e às variáveis maternas e socioeconômicas não abordadas no presente estudo.

Embora o estudo tenha produzido novos conhecimentos sobre o crescimento e desenvolvimento maxilar associado a fatores nutricionais e de saúde na infância precoce, podendo ser uma ferramenta útil para pesquisas posteriores que possam ser desenvolvidas em populações com outras características, algumas limitações devem ser destacadas. Variáveis socioeconômicas, o tipo de respiração, alimentação complementar e hábitos de sucção não nutritiva não foram abordadas.

Como pontos fortes do trabalho pode-se afirmar a característica de ser um estudo transversal aninhado numa coorte e utilizar análise de modelos de equações estruturais, já que permite estudar várias regressões simultaneamente e estabelecer relações diretas e indiretas entre as variáveis consideradas.

\section{Implicações para a saúde materna e infantil}

Pode-se considerar sob certo ponto de vista que o presente trabalho fez uso de uma abordagem interdisciplinar que envolveu profissionais da saúde de diferentes áreas de atuação e disciplinas e cujos resultados têm importantes implicações para a saúde materna e infantil.

Por essa razão, as associações encontradas têm importante significado para as áreas de saúde pública, pediatria, nutrição e odontologia, entre outras áreas e disciplinas com interesse no crescimento e desenvolvimento da criança. 
Condições prévias ao nascimento têm um papel importante no peso ao nascer e na saúde geral perinatal e na infância. Na infância precoce elementos marcantes como a alimentação, são dependentes da mãe na maioria dos casos. Fornecer ferramentas para as mães; educação, informação e apoio nesse proceso será de ajuda para a dupla mãe-filho. A promoção de desenvolvimento nas regiões que mais o precisam, por meio de políticas públicas que visem a melhorar a qualidade de vida dos seus habitantes é fundamental. Hospitais e centros de saúde amigos da mãe e da criança que estimulem e amparem práticas saudáveis tanto para a mãe, quanto para o filho são exemplos de iniciativas nessa direção.

O aleitamento materno não só favorece a saúde geral da criança, mas também representa benefícios para a mãe como seu efeito contraceptivo e a prevenção de câncer de mama, pode reduzir o risco de diabetes e de câncer de ovários (Victora et al., 2016).

Revisando o conhecimento registrado na literatura científica, constatam-se informações sobre o aleitamento materno, os tipos de aleitamento, e certas relações com a cavidade bucal e com o desenvolvimento das estruturas craniofaciais. A maioria dos estudos encontrados que relacionam o aleitamento e a cavidade bucal avaliam os efeitos na oclusão e hábitos de sucção não nutritiva.

O crescimento transversal diminuído pode resultar em oclusopatias e, consequentemente, na necessidade de tratamento ortodóntico na infância, na adolescência ou na adultez. O que por sua vez, representa um gasto importante para a economia da família e para at saúde pública; considerando que os tratamentos odontológicos são geralmente de alto custo. Implicando também custos para a saúde pública.

Por outro lado, segundo o grau de severidade, a má oclusão pode trazer como consequência uma baixa autoestima, além de outros problemas psicológicos, adentrando-se à subjetividade e afetando a qualidade de vida de adolescentes (Alvarez et al., 2010; Bönecker, 2014). 
Pode-se perceber que o campo da nutrição tem estabelecido vínculos investigativos com a saúde bucal como via de interdisciplinaridade visando a melhorar a abrangência do conhecimento produzido. Uma das principais relações conhecidas entre a nutrição e a saúde bucal é a ocorrência de cárie associada ao consumo de sacarose e outros carboidratos. Alterações no processo de formação dos dentes, também podem decorrer de uma situação de desnutrição: predispondo assim, a ocorrência de cárie. O nexo entre saúde bucal e práticas alimentares é forte, pois implica interdependência entre elas (Frazão et al., 2014b). Porém, os nexos com a pediatria ainda são muito fracos e é preciso fortalecer tais laços a fim de melhorar a saúde das crianças. Uma busca preliminar de literatura científica que relacionasse o peso ao nascer e o crescimento do osso maxilar mostrou ausência de estudos no tema.

A associação entre o peso ao nascer diminuído e o crescimento do osso maxilar pode vir a se tornar uma importante ferramenta predictora e subsidiar a prevenção de problemas de crescimento transversal na primeira infância; contribuindo de maneira considerável na prevenção de oclusopatias.

Além de contribuir para um adequado peso ao nascer da criança, políticas e programas que favoreçam o cuidado pré-natal e condições para garantir um parto a termo podem repercutir positivamente no crescimento transversal do maxilar. Do ponto de vista da Vigilância em Saúde, crianças com peso ao nascer diminuído, padrão inadequado de aleitamento materno e déficit nutricional para a idade podem apresentar maior probabilidade de desenvolver atrofia dos maxilares podendo, conforme a gravidade, redundar numa oclusopatia com importante impacto na qualidade de vida. 


\section{CONCLUSÕES}

Foi encontrado que o sexo, o peso ao nascer, o padrão de uso da mamadeira e o escore $Z$ do IMC para a idade estão associados à distância intermolar. O efeito de cada variável sobre o desfecho foi expressivo. Além disso, efeitos indiretos destas variáveis sobre a distância intermolar foram identificados.

Meninas, crianças com peso ao nascer diminuído, crianças com introdução da mamadeira muito precocemente e crianças com escore $Z$ do IMC para a idade diminuído têm maior probabilidade de ter crescimento transversal do maxilar diminuído.

Características do curso da vida da criança mostram-se associadas ao crescimento transversal do maxilar; o que traz várias implicações para a saúde de mães e filhos. Estratégias de promoção de saúde e prevenção de agravos são necessárias para favorecer condições sanitárias nas populações.

Os resultados são compatíveis às recomendações da OMS para a promoção do aleitamento materno exclusivo nos seis primeiros meses de vida considerando que o peso ao nascer apresentou um efeito total significativo sobre o crescimento transversal do maxilar, políticas e programas de promoção da saúde da criança devem ser fortalecidos, em virtude dos benefícios tanto para mãe quanto para a criança, além de atender e respeitar um direito humano essencial.

É preciso fortalecer ações orientadas ao cuidado da dupla mãe-filho, que propiciem condições de gestação, parto e puerpério que contribuam para a prevenção de agravos à saúde, dentre os quais as oclusopatias. 


\section{REFERÊNCIAS}

ABANTO, J. et al. El chupón: Riesgos y beneficios basados en evidencia científica. In: BONECKER, M. Problemas bucales en odontopediatría: uniendo la evidencia científica a la práctica clínica. Madrid: Ripano, 2014. Cap. 20, p. 258264.

ALAM, M. K. et al. Cone-beam computed tomography evaluation of Pont's index predictability for Malay population in orthodontics. J Nat Sci Biol Med, v. 6, n. Suppl 1, p. S113-7, 2015.

ALMEIDA, J. A. G. D. Amamentação: um híbrido natureza-cultura. Rio de Janeiro: Fiocruz, 1999.

ALMEIDA, S. P. T. D. M. A.; PAIXÃO, R. D. F.; VIEIRA, G. O. Influência do tipo de aleitamento, hábitos de sucção e má-oclusão: revisão sistemática da literatura. Jornal Brasileiro de Ortodontia e Ortopedia Facial, v. 10 , n. 57, p. 275-289, 2005.

AL-OMARI, I.K.; DUAIBIS, R.B.; AL-BITAR, Z.B. Application of Pont's Index to a Jordanian population. The European Journal of Orthodontics, v. 29, n. 6, p. 627631, 2007.

ALVARAN, N.; ROLDAN, S. I.; BUSCHANG, P. H. Maxillary and mandibular arch widths of Colombians. American Journal of Orthodontics and Dentofacial Orthopedics, v. 135, n. 5, p. 649-656, 2009.

ALVAREZ, J. A.; BÖNECKER, M.; RAGGIO, D. P. Impacto de los problemas bucales sobre la calidad de vida de niños. Revista Estomatológica Herediana, v. 20, n. 1, p. 38-43, 2010.

ALVES, E. Novo dicionário médico ilustrado inglés-português. São Paulo: Atheneu, 2004.

ANTONIO, M. A. R. G. M. et al. Fatores associados ao peso insuficiente ao nascimento. Rev. Assoc. Med. Bras., v. 55, n. 2, p. 153-157, 2009.

ARAUJO, A. M.; BUSCHANG, P. H. Conceitos atuais sobre o crescimento e desenvolvimento transversal dos maxilares e oportunidade de expansão mandibular. Rev. Dent. Press Ortodon. Ortop. Facial, v. 9, n. 3, p. 122-136, 2004.

AVILA, W. M. et al. Breast and Bottle Feeding as Risk Factors for Dental Caries: A Systematic Review and Meta-Analysis. PLoS One, v. 10, n. 11, p. e0142922, 2015. 
AZENHA, V. M. et al. Peso insuficiente ao nascer: estudo de fatores associados em duas coortes de recém-nascidos em Ribeirão Preto, São Paulo. Rev. paul. pediatr., v. 26 , n. 1 , p. 27-35, 2008

AZNAR, T. et al. Dental arch diameters and relationships to oral habits. Angle Orthod, v. 76, n. 3, p. 441-5, 2006.

BACCETTI, T.; REYES, B. C.; MCNAMARA, J. A., JR. Gender differences in Class III malocclusion. Angle Orthod, v. 75, n. 4, p. 510-20, 2005.

BAKER, J. L. et al. Maternal prepregnant body mass index, duration of breastfeeding, and timing of complementary food introduction are associated with infant weight gain. Am J Clin Nutr, v. 80, n. 6, p. 1579-88, 2004.

BANCO MUNDIAL (2017). Indicadores del desarrollo mundial: "Bebés con bajo peso al nacer (\% de nacimientos)". UNICEF, Estado Mundial de la Infancia, Childinfo y encuestas demográficas y de salud realizadas por Macro International. [acesso em 15 out 2017]. Disponível em: https://datos.bancomundial.org/indicador/SH.STA.BRTW.ZS

BARBAS, D. S. et al. Determinantes do peso insuficiente e do baixo peso ao nascer na cidade do Rio de Janeiro, Brasil, 2001. Epidemiol. Serv. Saúde, v. 18, n. 2, p. 161-170, 2009.

BARBIERI, M. A. et al. Risk factors for the increasing trend in low birth weight among live births born by vaginal delivery, Brazil. Revista de Saúde Pública, v. 34, n. 6, p. 596-602, 2000.

BARROS, H.; TAVARES, M.; RODRIGUES, T. Role of prenatal care in preterm birth and low birthweight in Portugal. J Public Health Med, v. 18, n. 3, p. 321-8, 1996.

BELLUZZO, R. H. L. et al. Maxillary constriction: are there differences between anterior and posterior regions? Dental Press Journal of Orthodontics, v. 17, n. 4, p. 1-6, 2012.

BERGLUND, S. K. et al. Marginally low birthweight increases the risk of underweight and short stature at three and a half years of age. Acta Paediatrica, v. 105, n. 6, p. 610-617, 2016.

BÖNECKER, M. Problemas bucales en odontopediatría: Uniendo la evidencia científica a la práctica clínica. Madrid: Ripano, 2014.

BOSHARI, T. et al. Differences in birthweight curves between newborns of immigrant mothers vs. infants born in their corresponding native countries: systematic overview. Paediatr Perinat Epidemiol, v. 27, n. 2, p. 118-30, 2013.

BRASIL. Ministério da Saúde. Departamento de Atenção Básica. Saúde da criança: nutrição infantil: aleitamento materno e alimentação complementar. Brasília, DF: Ministério da Saúde, 2009a. 
BRASIL. Ministério da Saúde. Centro Brasileiro de Análise e Planejamento. Pesquisa Nacional de Demografia e Saúde da Criança e da Mulher - PNDS 2006: dimensões do processo reprodutivo e da saúde da criança. Brasília, DF: Ministério da Saúde, 2009b.

BRASIL. Ministério da Saúde. Coordenação Nacional de Saúde Bucal. Projeto SB Brasil: Condições de Saúde Bucal da População Brasileira 2002 -2003 Resultados Principais. Brasília, DF: Ministério da Saúde, 2004.

BRASIL. Ministério da Saúde. Secretaria de Atenção à Saúde. Secretaria de Vigilância em Saúde. SB Brasil 2010: Pesquisa Nacional de Saúde Bucal: resultados principais / Ministério da Saúde. Secretaria de Atenção à Saúde. Secretaria de Vigilância em Saúde. Brasília, DF: Ministério da Saúde, 2012.

CARDOSO M. Nutrição em saúde coletiva. 1ª ed. São Paulo: Atheneu, 2014

CARDOSO, M. A. et al. Underlying factors associated with anemia in Amazonian children: a population-based, cross-sectional study. PLoS One, v. 7, n. 5, p. e36341, 2012.

CARRASCOZA, K. C. et al. Consequences of bottle-feeding to the oral facial development of initially breastfed children. J Pediatr, v. 82, n. 5, p. 395-7,2006.

CARRIZOSA, C. L.; ORTIZ, C. E. Exactitud del ancho de las arcadas dentarias: Índice de Pont en una población de mexicanos sin maloclusión. Revista ADM, v. 60, n. 3, p. 95-100, 2003.

CASTAÑO-CASTRILLÓN, J. J. et al. Relación entre peso al nacer y algunas variables biológicas y socioeconómicas de la madre en partos atendidos en un primer nivel de complejidad en la ciudad de Manizales, Colombia, 1999 al 2005. Revista Colombiana de Obstetricia y Ginecología, v. 59, n. 1, p. 20-25, 2008.

CASTELLINO, A. J.; SANTINI, R.; TABOADA, N. Crecimiento y desarrollo cráneo facial. Buenos Aires: Mundi, 1967.

CHEN, X.; XIA, B.; GE, L. Effects of breast-feeding duration, bottle-feeding duration and non-nutritive sucking habits on the occlusal characteristics of primary dentition. BMC Pediatr, v. 15, n. 1, p. 46, 2015.

CORREAA, C. D. C. et al. Interferência dos bicos ortodônticos e convencionais no sistema estomatognático: revisão sistemática. CoDAS, v. 28, n. 2, p. 182-189, 2016.

Descritores em Ciências da Saúde. DECS. Biblioteca virtual em saúde. [acesso em 19 dez 2016]. Disponível em: http://decs.bvs.br/cgibin/wxis1660.exe/decsserver/

DRUET, C.; ONG, K. K. Early childhood predictors of adult body composition. Best Practice \&Research Clinical Endocrinology \& Metabolism, v. 22, n. 3, p. 489502, 2008. 
FEARNE, J. M.; BROOK, A. H. Small primary tooth-crown size in low birthweight children. Early Hum Dev, v. 33, n. 2, p. 81-90, 1993.

FRAZÃO, P.; NARVAI, P. C. Epidemiologia das oclusopatias na dentadura decídua e os sistemas de saúde. In: CHEDID, S. J.Ortopedia e ortodontia para a dentição decídua: atendimento integral ao desenvolvimeto da oclusão infantil. São Paulo: Santos, 2013, p. 121-136.

FRAZÃO, P. Epidemiologia da oclusão dentária na infância e os sistemas de saúde. Tese (Doutorado em Saúde Pública) - Departamento de Prática de Saúde Pública, Faculdade de Saúde Pública, Universidade de São Paulo. São Paulo, 1999.

FRAZÃO, P. et al. Cárie dentária em escolares de 12 anos de idade em município sem água fluoretada na Amazônia Ocidental brasileira, 2010. Epidemiologia e Serviços de Saúde, v. 25, n. 1, p. 149-158, 2016.

FRAZÃO, P. et al. Food insecurity and dental caries in schoolchildren: a crosssectional survey in the western Brazilian Amazon. Eur J Oral Sci, v. 122, n. 3, p. 210-5, 2014a.

FRAZÃO, P. et al. Nutrição e saúde bucal. In: CARDOSO, M. A. Nutrição em saúde coletiva. $1^{\circ}$ ed. São Paulo: Atheneu, 2014b, p. 303-314.

GAMA, F. V. D. A. et al. Amamentaçäo e desenvolvimento: função e oclusão. Jornal brasileiro de ortodontia e ortopedia maxilar, v. 2, n. 11, p. 17-20, 1997.

GARCÍA, J.B. et al. Análisis de Carrea en niños con dentición temporal completa en el municipio de Mocoa (Putumayo). Acta Odontológica Colombiana; v. 6, n. 1, p. 69-82, 2016.

GARN, S. M.; OSBORNE, R. H.; MCCABE, K. D. The effect of prenatal factors on crown dimensions. The American Journal of Physical Anthropology, v. 51, n. 4, p. $665-78,1979$.

GHOSH, R. et al. Does the effect of air pollution on pregnancy outcomes differ by gender? A systematic review. Environ Res, v. 105, n. 3, p. 400-8, 2007.

GOMES, C. F. et al. Surface electromyography of facial muscles during natural and artificial feeding of infants. J Pediatr, v. 82, n. 2, p. 103-9, 2006.

GUARDO, A. J. Ortodoncia. Buenos Aires: Mundi, 1981.

HUERTA, S.F.; SALGADO, H.M. Peso al nacer de los niños y niñas derechohabientes del Instituto Mexicano del Seguro Social. Boletín médico del Hospital Infantil de México, v. 69, n. 1, p. 30-39, 2012.

IBGE- Instituto Brasileiro de Geografia e Estatística. Índice de desenvolvimento humano. [acesso em 15 out 2017]. Disponível em: https://cidades.ibge.gov.br/ 
INOUE, N.; SAKASHITA, R.; KAMEGAI, T. Reduction of masseter muscle activity in bottle-fed babies. Early Hum Dev, v. 42, n. 3, p. 185-93, 1995.

JOGAHARA, Y. O.; NATORI, M. Dental eruption sequence and eruption times in Erythrocebus patas. Primates, v. 53, n. 2, p. 193-204, 2012.

KHADILKAR, V. et al. Growth status of small for gestational age (SGA) Indian children from two socioeconomic strata. International Journal of Pediatric Endocrinology, v. 20, n. 4, p. 531-535, 2015.

KNOLL, L. R. A influência do aleitamento materno no crescimento e desenvolvimento craniofacial, sob o conceito da reabilitação neuroclusal. Ortodontia, v. 48, n. 2, p. 137-142, 2016.

LANGLAIS, R. P.; MILLER, C. S.; NIELD-GEHRIG, J. S. Atlas a color de enfermedades bucales. 1a Edición. México: Manual Moderno, 2011.

LOURENÇO, B. H. et al. Determinants of linear growth from infancy to schoolaged years: a population-based follow-up study in urban Amazonian children. BMC Public Health, v. 12, n. 1, p. 265, 2012.

LOURENÇO, B. H. et al. Influence of early life factors on body mass index trajectory during childhood: a population-based longitudinal analysis in the Western Brazilian Amazon. Matern Child Nutr, v. 11, n. 2, p. 240-52, 2015.

MAIA-NADER, M. et al. Factors associated with prolonged non-nutritive sucking habits in two cohorts of Brazilian children. BMC Public Health, v. 14, n. 1, p. 743, 2014.

MARCONDES, E. et al. Pediatria básica. 9.ed. São Paulo: Sarvier, 2003.

MAYORAL, J. Ortodoncia: principios fundamentales y práctica. Barcelona: Labor, 1977.

MAYORAL, J. et al. Ortodoncia : principios fundamentales y práctica. Barcelona: Labor, 1983.

MONDAL, B. Low birth weight in relation to sex of baby, maternal age and parity: a hospital based study on Tangsa tribe from Arunachal Pradesh. J Indian Med Assoc, v. 96, n. 12, p. 362-4, 1998.

MOYERS, R. E. Ortodontia. 3 ed. Rio de Janeiro: Guanabara-Koogan, 1979.

MUNIZ, P. T. et al. Child health and nutrition in the Western Brazilian Amazon: population-based surveys in two counties in Acre State. Cadernos de saude publica, v. 23, n. 6, p. 1283-1293, 2007.

MUTHÉN L.K.;MUTHÉN B.O. Mplus user's guide. 7ed. Los Angeles: Muthén \& Muthén,2012. 
NARBUTYTÉ I,; NARBUTYTÉ A.; LINKEVIČIENĖ L. Relationship between breastfeeding, bottle-feeding and development of malocclusion. Stomatologija, Baltic Dental and Maxillofacial Journal, v. 15, n. 3, p. 67-72, 2013.

NASCIMENTO, L.F.C.; MACHIN, A.B.; SANTOS, D.A.A.D. Are there differences in birth weight according to sex and associations with maternal exposure to air pollutants? A cohort study. Sao Paulo Med J, v. 135, n. 4, p. 347-354, 2017.

O'CONNELL, S. et al. Medical, nutritional, and dental considerations in children with low birth weight. Pediatr Dent, v. 31, n. 7, p. 504-12, 2009.

OMS - Organização Mundial da Saúde. Estrategia mundial para la alimentación del lactante y del niño pequeño. Ginebra: OMS, 2003.

OMS - Organização Mundial da Saúde; UNICEF - Fondo de las Naciones Unidas para la Infancia. Protección, promoción y apoyo de la lactancia natural : la función especial de los servicios de maternidad. Ginebra: OMS, 1989.

OMS - Organização Mundial da Saúde. Curso de Capacitación sobre la evaluación del crecimiento del niño. Ginebra: OMS, 2008.

OMS - Organização Mundial da Saúde. Indicadores para evaluar las prácticas de alimentación del lactante y del niño pequeño: conclusiones de la reunión de consenso llevada a cabo del 6 al 8 de noviembre de 2007 en Washington, DC, EE.UU. Ginebra: OMS, 2009.

OMS - Organização Mundial da Saúde. Child growth standards. [acesso em 19 out 2017]. Disponível em: http://www.who.int/childgrowth/standards/es/

OMS - Organização Mundial da Saúde. Ginebra. Disponível em: http://www.who.int/maternal child adolescent/topics/newborn/nutrition/breastfeedi ng/es/. [acesso em 19 out 2017].

ONIS, M. D. et al. Development of a WHO growth reference for school-aged children and adolescents. Bulletin of the World Health Organization, v. 85, n. 9, p. 660-667, 2007.

OPS - Organização Pan-americana da Saúde; OMS - Organização Mundial da Saúde. El valor incomparable de la leche materna. 1a ed. Washington: OPS, 1972.

PEABODY, J. W.; GERTLER, P. J.; LEIBOWITZ, A. The policy implications of better structure and process on birth outcomes in Jamaica. Health Policy, v. 43, n. 1, p. 1-13, 1998.

PERES, K. G. et al. Effect of breastfeeding on malocclusions: a systematic review and meta-analysis. Acta Paediatr, v. 104, n. 467, p. 54-61, 2015. 
PERES, K. G.; FRAZÃO, P.; RONCALLI, A. G. Epidemiological pattern of severe malocclusions in Brazilian adolescents. Rev Saúde Pública, v. 47, n. (Suppl 3), p. 109-117, 2013.

PNUD - Programa das Nações Unidas para o Desenvovimento no Brasil. Disponível em: http://www.br.undp.org/content/brazil/pt/home/. [acesso em 20 out 2017].

PNUD - Programa das Nações Unidas para o Desenvolvimento, INSTITUTO DE PESQUISA ECONÔMICA APLICADA E FUNDAÇÃO JOÃO PINHEIRO. Atlas do desenvolvimento humano no Brasil. [acesso em 15 out 2017]. Disponível em: http://atlasbrasil.org.br/2013/pt/

PONCE, J. A. B.; BARRIAL, Y. M.; SOLíS, U. S. Desarrollo del complejo naso maxilar en el niño de bajo peso al nacer. Estudio comparativo. Revista CES Odontología, v. 7, n. 2, p. 49-54, 1994.

RASPALL, G. Cirugía maxilofacial: patología quirurgica de la cara, boca, cabeza y cuello. Madrid: Editorial Médica Panamericana, 1997.

RATHI, M. K.; FIDA, M. Applicability of Pont's index in orthodontics. J Coll Physicians Surg Pak, v. 24, n. 4, p. 256-60, 2014.

ROUSSET, M. M.; BOUALAM, N.; DELFOSSE, C. Occlusion and rhythm of eruption. Bull Group Int Rech Sci Stomatol Odontol, v. 43, n. 2, p. 53-61, 2001.

ROUSSET, M. M. et al. Emergence of permanent teeth: secular trends and variance in a modern sample. J Dent Child, v. 70, n. 3, p. 208-14, 2003.

SALONE, L. R.; VANN, W. F., JR.; DEE, D. L. Breastfeeding: an overview of oral and general health benefits. The Journal of the American Dental Association, $v$. 144, n. 2, p. 143-151, 2013.

SÁNCHEZ-MOLINS, M. et al. Comparative study of the craniofacial growth depending on the type of lactation received. European Journal of Paediatric Dentistry, v. 11, n. 2, p. 87-92, 2010.

SANKAR, M. J. et al. Optimal breastfeeding practices and infant and child mortality: a systematic review and meta-analysis. Acta Paediatr, v. 104, n. S467, p. 3-13, 2015.

SANTOS NETO, E. T. D. et al. The influence of sucking habits on occlusion development in the first 36 months. Dental Press Journal of Orthodontics, v. 17, n. 4, p. 96-104, 2012.

SEOW, W. K. et al. A study of primary dental enamel from preterm and full-term children using light and scanning electron microscopy. Pediatric Dentistry, v. 27, n. 5, p. 374-379, 2005. 
SIMÕES, W. A. Ortopedia funcional dos maxilares: vista através da reabilitação neuro-oclusal. $1^{\text {a }}$ ed. São Paulo: Santos, 1985.

SIRIWAT, P. P.; JARABAK, J. R. Malocclusion and facial morphology is there a relationship? An epidemiologic study. Angle Orthod, v. 55, n. 2, p. 127-38, 1985.

STEDMAN, T. L. Stedman's medical dictionary for the dental professions. Filadélfia: Lippincott Williams \& Wilkins, 2012.

THOMAZ E. B. A. F. et al. Is Malnutrition Associated with Crowding in Permanent Dentition? International Journal of Environmental Research and Public Health, v. 7, n. 9, p. 3531-3544,2010

UNICEF - United Nations Children's Fund e OMS - Organização Mundial da Saúde. Low birthweight: country, regional and global estimates. New York: UNICEF, 2004. [acesso em 24 mar 2017]. Disponível em: http://apps.who.int/iris/bitstream/10665/43184/1/9280638327.pdf

UNICEF - Fondo de las Naciones Unidas para la Infancia. Progreso para la infancia. Un balance sobre la nutrición. n. 4. Nueva York: UNICEF, 2006. [acesso em 24 mar 2017]. Disponível em: https://www.unicef.org/spanish/publications/files/Progreso para la infancia No. 4.pdf

VICTORA, C. G. et al. Breastfeeding in the 21st century: epidemiology, mechanisms, and lifelong effect. The Lancet, v. 387, n. 10017, p. 475-490, 2016.

VIGGIANO, D. et al. Breast feeding, bottle feeding, and non-nutritive sucking; effects on occlusion in deciduous dentition. Arch Dis Child, v. 89, n. 12, p. 11211123, 2004.

VOLDNER, $N$. et al. Determinants of birth weight in boys and girls. human_ontogenetics, v. 3, n. 1, p. 7-12, 2009.

ZHU, Y. et al. Longer breastfeeding duration reduces the positive relationships among gestational weight gain, birth weight and childhood anthropometrics. Journal of Epidemiology and Community Health, v. 69, n. 7, p. 632, 2015.

ZÖLLNER, M. S. A. D. C.; JORGE, A. O. C. Aleitamento materno: caminho natural para a saúde. JBP rev. Ibero-am. odontopediatr. odontol. bebê, v. 8, n. 42, p. 135-142, 2005. 


\section{ANEXOS}

\section{Anexo 1. Termo de consentimento livre e esclarecido - TCLE}

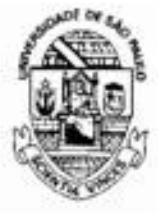

UNIVERSIDADE DE SÃO PAULO Faculdade de Saúde Pública

Av. Dr. ARNALO, 715 - Sĩo PAULo, SP - CEP 01246-904

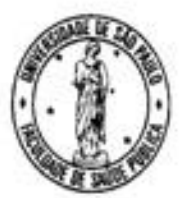

PESQUISA DE SAÚDE PÚBLICA

TERMO DE CONSENTIMENTO LIVRE E ESCLARECIDO

Prezado(a) Senhor(a):

Meu nome é Doroti Benicio (RG no 4.474.375-0/SSP-SP) e sou cirurgiā-dentista e pesquisadora da Faculdade de Saúde Pública (FSP) da Universidade de São Paulo (USP). Estou realizando uma pesquisa de saúde pública, sob supervisão do Prof. Dr. Paulo Capel Narvai, sobre as condiçōes dos dentes e gengivas de crianças em idade escolar que moram em Acrelândia, com apoio institucional da Secretaria da Saúde e do Ministério da Saúde.

Para conhecer a situaçăo da saúde da boca das crianças, estou examinando essa parte do corpo e realizando entrevistas com os seus pais ou responsáveis. Por esse motivo eu estou convidando vocé a participar da pesquisa, respondendo a algumas perguntas sobre o assunto $e$. também, pedindo sua autorizaçăo para examinar os dentes e gengivas do menor - O exame, feito com materiais esterilizados, e de acordo com normas e padrōes definidos pela Organizaçăo Mundial da Saúde, è praticamente igual ao realizado nos consultórios de dentistas antes dos tratamentos e apresenta riscos minimos, pois è feita apenas observação das partes da boca, sem aplicar nenhum remédio, nem retirar nenhuma parte de dentes e gengivas. Seu nome e suas respostas as minhas perguntas năo serăo fomecidas para ninguém de modo a identificá-lo(a). Se for observado algum problema dentário que necessite da avaliaçăo de um dentista, ou de um profissional do setor, eu informarei o menor e vocé por escrito.

Se o(a) senhor(a) quiser saber mais sobre a pesquisa, pode perguntar o que quiser. Se concordar que eu faça as perguntas e examine o menor, entáo é necessário seu aceite no termo de consentimento abaixo, do qual poderá desistir a qualquer tempo, mesmo após a assinatura. Se tiver alguma dúvida e preferir perguntar ao Responsável pela pesquisa, entāo ligue para o Professor Cleber Ronald Inácio dos Santos, na Universidade Federal do Acre (UFAC), membro da coordenaçấo local da pesquisa, no telefone: 68 - 3901-2585 (se preferir, use o celular 68 - 9991-4039) ou procure-0 no Centro de Ciências da Saúde e do Desporto, na UFAC (BR 364 - KM 04 - Distrito Industrial - CEP 69915-900 - Rio Branco, AC). A realizaçăo desta pesquisa foi autorizada pelos Comités de Ética em Pesquisa da Faculdade de Saúde Pública da USP (Av. Dr. Arnaldo, 715 CEP 01246-904 São Paulo SP - Telefones: 11 - 3061-7779) e da UFAC. Caso vocé necessite de algum esclarecimento, pode escrever, telefonar ou enviar mensagem eletrônica para o Comité da FSP/USP (e-mail: coep@isp.usp.br).

Grata por sua colaboração,

DOROT BENICIO

responsável pela entrevista es exames

Termo de Consentimento Livre e Esclarecido

Declaro estar ciente das condiçóes da pesquisa sobre saúde bucal de crianças de Acrelândia, aceito participar e autorizo o exame do(a) menor:

Nome do aluno:

Data: / 120

Nome do responsável:

Assinatura do responsável: em: 120 


\title{
Anexo 2. Aprovação do comitê de ética em pesquisa - COEP/FSP
}

\author{
COMITÊ DE ÉTICA EM PESQUISA - COEP/FSP \\ Universidade de São Paulo \\ Faculdade de Saúde Pública
}

OF.COEP $/ 297 / 09$

São Paulo, 30 de outubro de 2009.

Prezado(a) Pesquisador(a) e Orientador(a),

o Comitê de Ética em Pesquisa da Faculdade de Saúde Pública da Universidade de Săo Paulo - COEP/FSP, analisou em sua 8.a/09 Sessão Ordinária realizada em 23/10/2009, de acordo com a Resolução N. ${ }^{\circ}$ 196/96 do Conselho Nacional de Saúde - CNS e suas complementares o protocolo de pesquisa n.o 1984, intitulado "SAÚDE BUCAL DE CRIANÇAS NA AMAZÔNIA OCIDENTAL BRASILEIRA: ESTUDO SECCIONAL ANINHADO EM COORTE", área temática GRUPO III, sOb responsabilidadie do(a) pesquisador(a) Paulo Capel Narvai e considera o protocolo de pesquisa acima intitulado APROVADO.

Cabe lembrar que conforme Resolução $C N / 196 / 96$, são deveres do (a) pesquisador (a): 1. Comunicar, de imediato, qualquer alteração no projeto e aguardar manifestação deste CEP (Comitê de Ética em Pesquisa), para dar continuidade à pesquisa; 2. Manter sob sua guarda e em local sequro, pelo prazo de 5 (cinco) anos, os dados da pesquisa, contendo fichas individuais e todos os demais documentos recomendados pelo CEP, no caso eventual auditoria; 3. Comunicar, formalmente a este Comitê, quando do encerramento deste projete; 4. Elaborar e apresentar relatórios parciais e final; 5. Justificar, perante o CEP, interrupção do projeto ou a não publicação dos resultados.

Atenciosamente,

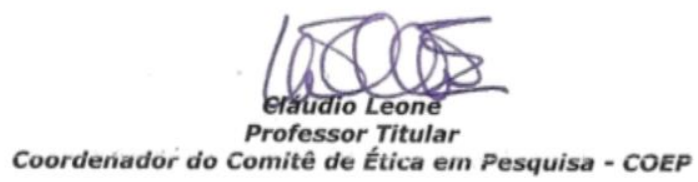

Ilm. ${ }^{\circ} \mathrm{Sr}$.

Prof. Dr. Paulo Capel Narvai

Departamento de Prática de Saúde Pública

Faculdade de Saúde Pública - USP

Av. Dr. Arnaldo, 715 - Assessoria Acadêmica - CEP: 01246-904 - São Paulo - SP Telefones: (55-11) 3061-7779/7742 e-mail: coep@fsp.usp.br site www.fsp.usp.br 